\title{
Technical Support Document For A Proposed IECC Glazing Orientation Restriction
}

\author{
Z Todd Taylor
}

January 2009

Pacific Northwest

NATIONAL LABORATORY

Proudly Operated by Battelle Since 1965 


\title{
DISCLAIMER
}

This report was prepared as an account of work sponsored by an agency of the United States Government. Neither the United States Government nor any agency thereof, nor Battelle Memorial Institute, nor any of their employees, makes any warranty, express or implied, or assumes any legal liability or responsibility for the accuracy, completeness, or usefulness of any information, apparatus, product, or process disclosed, or represents that its use would not infringe privately owned rights. Reference herein to any specific commercial product, process, or service by trade name, trademark, manufacturer, or otherwise does not necessarily constitute or imply its endorsement, recommendation, or favoring by the United States Government or any agency thereof, or Battelle Memorial Institute. The views and opinions of authors expressed herein do not necessarily state or reflect those of the United States Government or any agency thereof.

\author{
PACIFIC NORTHWEST NATIONAL LABORATORY \\ operated by \\ BATTELLE \\ for the \\ UNITED STATES DEPARTMENT OF ENERGY \\ under Contract DE-AC05-76RL01830
}

Printed in the United States of America
Available to DOE and DOE contractors from the Office of Scientific and Technical Information,
P.O. Box 62, Oak Ridge, TN 37831-0062;
ph: (865) 576-8401
fax: (865) 576-5728
email: reports@adonis.osti.gov

Available to the public from the National Technical Information Service 5301 Shawnee Rd., Alexandria, VA 22312

ph: (800) 553-NTIS (6847)

email: orders@ntis.gov <http://www.ntis.gov/about/form.aspx>

Online ordering: http://www.ntis.gov 


\section{Technical Support Document For A Proposed IECC Glazing Orientation}

ZT Taylor

January 2009

Prepared for the U.S. Department of Energy under Contract DE-AC05-76RL01830

Pacific Northwest National Laboratory

Richland, Washington 99352 


\section{Summary}

This report documents the development of an approach to regulating glazing orientation in the International Energy Conservation Code (IECC). To date, the IECC has never effectively regulated the orientation of glazing in new homes. Although one compliance path (Performance) does give credit for good orientation and penalty for bad orientation, the existence of other compliance paths that are blind to orientation means that poorly ${ }^{1}$ oriented homes can be built without restriction.

The proposed approach to regulating glazing orientation is the addition of a prescriptive limit on the amount of west-facing glazing on a home. Glazing facing west has the greatest impact on cooling loads for a number of reasons, including the solar geometry (low sun angle), high outdoor temperatures late in the day, and the need for air conditioning when occupants return home from daily activities. West-facing glazing also greatly affects peak (demand) loads. The proposed approach is expressed in units of absolute area $\left(\mathrm{ft}^{2}\right)$ rather than as a percentage of floor area or wall area, meaning that it is less restrictive for smaller homes than for larger ones. The specific west-facing glazing area limit $\left(110 \mathrm{ft}^{2}\right)$ was chosen to impose minimal restrictions on small starter homes while still putting pressure on builders to orient average and large homes sensibly.

The proposed approach regulates only one face of a typical four-sided home-the one that faces west. The definition of "west-facing” includes glazing facing within 45 degrees south of west (225 degrees) and 30 degrees north of west (300 degrees), a range in which the proposed limit proves to be advantageous based on energy simulations. Because only one building face is involved, enforcement of this regulation is straightforward. And because the requirement is not expressed as a percentage, there is no need to measure or otherwise verify a home's wall or floor area. Only the actual area of glazing units on the west face of the building must be verified.

The energy impact of the proposed west-facing glazing restriction was assessed by a parametric simulation study. More than 180,000 DOE-2 simulations were run to estimate the primary impact of the restriction in a large number of U.S. locations as well as the sensitivity of those results to various related building parameters (house size, total glazing area as a percentage of floor area, glazing SHGC, and departure of orientation from due west) and to the manner in which a builder might respond to the restriction when contemplating a house plan that violates it (reduce west-facing glazing to meet the restriction, relocate some west-facing glazing to other building faces, or rotate the building).

The simulation study shows that, for a typical home with most of its glazing on two sides (facing the street and the backyard), the proposed restriction reduces cooling energy consumption by anywhere from a few percent to 15 percent or more, depending on the assumed builder response, and does so without detrimental impacts on heating energy

\footnotetext{
${ }^{1}$ By "poorly" we mean from the perspective of energy consumption. A home that collects a lot of solar heat in the summer and/or little solar heat in the winter is considered poorly oriented.
} 
consumption. Relocating glazing has the smallest benefit; reducing overall glazing has slightly more benefit; and rotating the building has—by far-the greatest benefit. Peak cooling loads are reduced by similar amounts.

The impact on heating energy consumption ranges from a significant reduction to a slight increase. In virtually all situations analyzed, cooling benefits exceed any heating detriments in terms of overall energy costs.

\section{Background}

\section{Goal}

Our goal is simply to design an approach to regulating glazing orientation in the IECC. The primary intent is to discourage the construction of homes that collect inordinate amounts of solar heat in the summer. A secondary consideration is encouraging homes that do collect solar heat in the winter. Within that framework, we hope to minimize the impact and cost to small "starter" homes - for which limited budgets and small lot sizes may restrict builders' flexibility in constructing buildings with advantageous solar orientation —and develop an approach that is easy to inspect and enforce.

\section{Discussion}

The singular focus of the code change discussed here is reducing detrimental solar gains through a home's windows and glazed doors. Although solar gains can be beneficial in reducing a home's heating requirements, achieving that benefit without increasing summer cooling loads and/or overheating the home during some winter hours requires careful design. It is beyond the scope of this work to develop a code provision that properly relates glazing area and orientation, shading, and thermal mass. However, within the limited scope of reducing detrimental solar gains during the cooling season, the analysis is relatively straightforward. Simply reducing the amount of glazing will reduce cooling loads, and reducing west-facing glazing achieves the greatest benefit. Apart from that, the primary factors of interest are the concomitant impact on heating loads and the pragmatic concerns of building function and aesthetics.

Whole-building energy simulations were used to calculate both the cooling benefit and any heating detriment of glazing area reductions. A large number of parametric analyses were conducted to evaluate the impact of the contemplated code change on energy consumption (heating and cooling), energy cost (heating + cooling), and cooling peak under various scenarios of climate, home size and orientation, glazing properties, and overall glazing amount.

\section{History}

\section{How The Current Code Deals With Glazing Orientation}

The IECC currently does not regulate glazing orientation. The Performance compliance path does give credit or penalty for specific glazing configurations, but imposes no fundamental limit on "bad" glazing arrangements. In fact, the design of the orientation provisions of the current Performance path actually encourages homes with higher energy 
consumption in some cases. Because the Performance path's standard reference design has glazing equally distributed to all four cardinal directions, the vast majority of houses will either get substantial credit or substantial penalty depending on the orientation of the predominant glazing. For those that would get substantial penalty, builders may find that the homes comply more easily via the prescriptive path. For those that would get substantial credit, builders are free to reduce the efficiency of other features such as insulation or glazing U-factor. This latter phenomenon results from the performance path giving credit for a home feature not regulated by the prescriptive path and having a baseline for that feature that is very atypical-few homes have equally distributed orientation. This is often referred to as a "free rider" effect; eliminating it is one goal of this work.

\section{Glazing Percentage Restrictions}

A common suggested approach to limiting detrimental solar gains in residences is to place a prescriptive limit on the total area of glazing. To our knowledge this approach has always been implemented as a limit on the glazing amount as a percentage of either the home's conditioned floor area or gross wall area. For example, the prescriptive tables of the 2003 IECC [Tables 502.2.4(1-9)] have increasingly stringent envelope requirements for higher window-wall ratios. Unfortunately, expressing glazing area limits as percentages has some rather serious drawbacks. These are detailed in a white paper accessible at http://www.energycodes.gov/implement/pdfs/wwr_elimination.pdf and are briefly summarized here:

First, code provisions expressed as percentages of wall or floor area greatly increase the complexity of the code and the effort required for enforcement. Under a percentagebased window area restriction, a home's specific energy efficiency requirements cannot be known until its design is finalized, making it impossible for builders and code officials to memorize the code's major requirements. Simple design changes after the fact-such as shortening the home by a small amount — can render a previously complying home out of compliance, complicating matters for a custom builder. Further, time required for inspection increases considerably, as not only must glazing area be measured, but wall or floor area as well. Plan reviewers must likewise do area take-offs of the entire building (walls, floor area and windows) to verify a plan's compliance with the code. Wall and floor areas can be difficult to establish unambiguously in the presence of dormers, kneewalls, A-frames, mansard roofs, walk-out basements, and other geometrical complications.

Second, expressing glazing area restrictions in terms of a percentage results in some irrational code behaviors and perverse incentives. It is easy to show, for example, that a code that is sensitive to window-floor ratio (WFR) will generally allow less efficient envelopes on larger homes and homes with inefficient aspect ratios than on smaller homes or homes with efficient "box" shapes. By extension, many energy-wise design changes can be discouraged, and energy-unwise changes encouraged, by a code sensitive to WFR or window-wall ratio (WWR). For example, if a home design that minimally complies with the code is modified to lengthen it by a couple of feet, the net result would be a larger home with higher energy consumption. A WFR-sensitive code, however, 
would permit that home to reduce its envelope efficiency. Similarly, under a WWRsensitive code, one strategy to bring a noncompliant home into compliance might be to change from eight-foot to ten-foot ceilings, a change that would increase wall area and, hence, energy consumption.

DOE led an effort in the code development cycle for the 2004 Supplement to the IECC to remove the percentage-based glazing area limits from the code. This successful effort reduced the size of the residential code by more than half and greatly simplified its specifications.

One goal of this effort is to develop a specification that effectively regulates badly oriented glazing without reintroducing the problems of percentage-based glazing requirements.

\section{How Others Have Approached the Problem}

The state of California recently implemented orientation restrictions in some locations in its Title-24 residential code. ${ }^{2}$ The California restriction is expressed as a percentage of floor area, where west-facing glazing in excess of $5 \%$ of floor area is disallowed without compensating improvements to other house features. The west-facing restriction is part of an overall $20 \%$ limit on total glazing area. Notably, for an average home having 2200 $\mathrm{ft}^{2}$ of conditioned floor area, $5 \%$ glazing is $110 \mathrm{ft}^{2}$, exactly the value we are proposing. The primary difference between the two is that the absolute area approach has a progressively greater impact on larger homes and a smaller impact or no impact on smaller homes.

\section{Approach}

Our proposed approach to regulating glazing orientation is to put a simple restriction on west-facing glazing area. The maximum allowable area would be expressed in terms of absolute area $\left(\mathrm{ft}^{2}\right)$ rather than as a percentage of floor or wall area. As discussed in the following paragraphs, the proposed code provision would be a maximum allowable westfacing glazing area (MaxWGA) of $110 \mathrm{ft}^{2}$.

\section{Why an absolute area and not a percentage?}

Specifying glazing orientation requirements in term of absolute area results in a number of benefits. First, as discussed above, it avoids the numerous complications inherent in any code provision expressed in terms of a percentage. An absolute limit guarantees that the incentives are never perverse - the code always pushes builders toward reducing energy consumption, and it puts greater pressure to improve efficiency on higher-energy homes than on lower-energy homes.

Second, an orientation requirement based on absolute area greatly simplifies inspection and enforcement. The limit is a single number that can be easily memorized, requires plan reviewers to do take-offs on only one building face, and allows inspectors to

\footnotetext{
${ }^{2}$ http://www.energy.ca.gov/2005publications/CEC-400-2005-005/chapters_4q/3_Building_Envelope.pdf
} 
measure/verify only the glazing area on one building face; the remaining windows, wall area, and floor area needn't be verified.

Third, an absolute area-based requirement preserves flexibility for builders in several ways. Small "starter" homes, for example, will often be completely unaffected by the restriction since many small home plans have less than $110 \mathrm{ft}^{2}$ of glazing on any face. Also, because most home designs have windows concentrated on two faces of the building - facing the street and backyard, respectively — even larger homes built on advantageously-oriented lots will often be unaffected by the restriction. One option for builders is to design lot layouts such that most of the lots (say, $75 \%$ or $80 \%$ ) are advantageously oriented. The lots that cannot be so oriented can be reserved for smaller homes that are not impacted by the $110-\mathrm{ft}^{2}$ limit. In any case, the code's performance path may be used to gain additional flexibility by exceeding the west-facing glazing area limit if other compensating improvements are made to other building features. In IECC parlance, the west-facing glazing area limit would be a "prescriptive" limit, not a "mandatory" limit.

\section{Why regulate only one face of the building?}

A key observation related to new housing is that many if not most homes are built on small lots with minimal street frontage. A number of factors influence this, including the high cost of land development; the cost savings inherent in minimizing the total length of streets and associated water, sewer, and electrical systems; environmental concerns that inspire a minimization of hard-top streets; and an increasing scarcity of developable land in many places. The important result is that new homes tend to have a large majority of their windows on two faces of the home-facing the street and backyard, respectively.

Consequently, whether a home is advantageously oriented is often largely a function of whether its street is oriented primarily east-west or primarily north-south. Our proposed approach to regulating glazing orientation takes advantage of this phenomenon. Because side yards are typically very small and neighboring homes very close, new housing has very few windows on the side faces, so it is unnecessary to regulate glazing on those faces. The remaining (majority) of windows will be distributed between the front and back faces of the home in proportions that are at least similar if not close to equal. Therefore, since the primary goal of this change proposal is to motivate builders to orient buildings advantageously, it is only necessary to regulate one face of the building to achieve most of the potential benefits.

\section{What about home designs that exceed the 110-ft ${ }^{2}$ limit?}

To comply a home design with west-facing glazing area that would exceed the code's limit, builders have essentially four remedies:

1. Relocate some west-facing windows to other building faces.

2. Reduce overall glazing area by eliminating or reducing the size of some westfacing windows.

3. Rotate the entire home so that less glazing faces west. 
4. Comply via the performance path to improve the efficiency of other home features in trade for the higher west-facing glazing area.

The fourth option above is a completely general solution that allows a virtually unlimited number of options for compliance, all of which, by definition, have essentially the same energy consumption. The first three listed options are more interesting because they represent the likely simple remedies to out-of-compliance home designs and, in some sense, define the potential energy savings of this proposed code change.

The savings that will accrue from these three remedies varies with a number of parameters, but they do all save energy. The remedies are ordered above according to generally increasing energy savings relative to the baseline home (the one that would have had too much west-facing glass). That is, while relocating some west-facing glazing to other building faces saves energy, eliminating that glazing altogether would save more and, in most cases, reorienting the whole house would save even more.

\section{Cost}

The cost of implementing this proposed code change is quite variable, but rarely large. Indeed, in many cases it would be negative.

The proposed code provision will have no effect on many small homes, and hence no cost. Homes that are impacted by the west-facing glazing area restriction can be brought into compliance by several options, many of which will have low or no cost. For example, with the exception of very large homes, almost any house design will comply without change if it is oriented advantageously. In other cases, a builder may choose to reduce the west-facing glazing area by eliminating or reducing the size of some windows, either of which would actually lower the cost of construction. In cases where a builder relocates some west-facing windows to other building faces, other than upfront redesign costs that would generally be amortized over a large number of homes, the cost would be zero.

Large homes present the highest potential for construction cost increases. A very large home with (initially) a large west-facing glazing area may be difficult to bring into compliance by reducing or relocating west-facing glazing because the amount of glazing exceeding the $110-\mathrm{ft}^{2}$ limit can be large. In such cases rotating the home on the lot, building it on a different lot in the same subdivision (and reserving the first lot for a smaller home), or complying via performance-path trade-off may be the viable options. Only the latter of these has the potential to cause a direct increase in the cost of construction.

A final consideration with respect to cost is the fact that virtually any change a builder might make to bring a home into compliance with this proposed change would have the effect of reducing the home's peak cooling load. In many situations that load reduction might allow a reduction in the size of the home's air conditioner, which would lower the 
cost of the home. A later section of this report quantifies the likely load reduction under various scenarios.

\section{Energy Analysis}

An energy analysis of this proposed code change was conducted for two purposes: affirming that the format and specification of the west-facing glazing limit indeed accomplish the goals discussed above, and establishing a basis for estimating the overall energy savings attributable to the change. The energy analysis is based on hour-by-hour simulations using the DOE-2 building simulation software. A simple prototype home was simulated in a large number of locations to evaluate the code change's impact in a comprehensive range of U.S. climates. Because the interactions between glazing orientation and other building loads is complex and the correlation between local temperatures and solar intensity complex, we conducted energy simulations for each of the 239 available TMY2 climate locations. ${ }^{3}$ Further, a large suite of parametric analyses was used to evaluate impacts on a broad variety of building configurations and to identify any detrimental outcomes or perverse incentives.

Parameters evaluated include the west-facing glazing area limit, the size of the home (conditioned floor area), the overall glazing area (expressed as a percentage of floor area), the solar heat gain coefficient (SHGC) of the home's glazing, and the definition of "west facing" (degrees of deviation from true west that are included in the restriction). For various levels of each of these parameters, the DOE-2 program was used to evaluate the impact on heating and cooling loads of the three remedies a builder might employ to bring a home into compliance with the new code provision.

\section{DOE-2 Prototype}

Energy simulations were performed for a simple, rectangular (aspect ratio 1.5:1), twostory residence with standard frame construction, and vented crawlspace foundation. Heating and cooling are by gas furnace and electric air conditioning, respectively, although the system particulars are of only secondary importance because the analysis looks only at relative changes in space conditioning loads and evaluates heating and cooling separately. That is, the analysis is focused on percent change in cooling and percent change in heating for various glazing configurations, relative to the standard baseline home. We also include a cursory assessment of the combined heating plus cooling impact based on energy costs to ensure that the proposed code revision's impact is a net benefit.

Apart from the parametric variables under study, the home's properties are set to be consistent with the 2006 IECC, the defined baseline for DOE's goal of 30\% IECC improvement. A roughly average home is used as the baseline. General assumptions about the prototype residence as well as baseline values of variable parameters are shown in Table 1.

\footnotetext{
${ }^{3}$ http://rredc.nrel.gov/solar/old_data/nsrdb/tmy2/
} 


\begin{tabular}{|l|l|}
\hline \multicolumn{2}{|c|}{ Table 1: Major Assumptions for Simulation of Baseline Prototype } \\
These describe the prototype home used to assess the energy impact of the proposed \\
code change. Several of these parameters were varied in a subsequent parametric \\
analysis.
\end{tabular}

Table 2 discusses the three remedies a builder might employ to achieve compliance with the limit on west-facing glazing area. No remedies based on the code's simulated performance compliance path are evaluated.

\section{Energy Impact Analysis}

The primary results of the DOE-2 simulations are estimates of reductions in cooling energy resulting from three possible remedies a builder might employ to bring a home with more than $110 \mathrm{ft}^{2}$ of west-facing glazing area into compliance. These remedies and descriptions of how they are employed in the simulations are shown in Table 2. The analysis additionally looks at the impact of the proposed change on heating loads as well as the aggregate (heating + cooling) impact based on energy costs. 
Table 2: Descriptions of Remedies Builders May Employ to Comply with a West-Facing Glazing Area Restriction

These are the scenarios simulated to estimate the energy savings attributable to the proposed west-facing glazing area restriction.

\begin{tabular}{||l|l||}
\hline \multicolumn{1}{|c|}{ Remedy } & \multicolumn{1}{|c|}{ Description } \\
\hline $\begin{array}{l}\text { Relocate excess west-facing } \\
\text { faces }\end{array}$ & $\begin{array}{l}\text { Any home design that would have west-facing glazing } \\
\text { area in excess of the limit }\left(110 \mathrm{ft}^{2}\right) \text { would be modified } \\
\text { by relocating some windows to other building faces to } \\
\text { bring the west-facing area down to the limit. The } \\
\text { energy simulations assume that any relocated glazing is } \\
\text { put equally on the north and south faces of the } \\
\text { building. The rationale for this assumption is that } \\
\text { relocations are most likely to involve moving a west- } \\
\text { facing window to another wall in the same room, and } \\
\text { that it is more likely such relocations will be to } \\
\text { adjacent (north or south) walls than to the opposite side } \\
\text { of the house, which would most likely mean moving } \\
\text { the window to a different room. }\end{array}$ \\
\hline Reduce overall glazing area & $\begin{array}{l}\text { This assumes the builder will either eliminate one or } \\
\text { more west-facing windows or reduce their sizes in } \\
\text { by eliminating some west- } \\
\text { facing glazing } \\
\text { to the limit (110 ft }{ }^{2} \text {.) This usually results in more } \\
\text { energy savings than a relocation because not only are } \\
\text { the detrimental aspects of west-facing glazing reduced, } \\
\text { but the overall glazing area is reduced, which generally } \\
\text { improves matters for both heating and cooling in most } \\
\text { climates. }\end{array}$ \\
\hline$\underline{\text { Rotate the building }}$ & $\begin{array}{l}\text { This assumes the builder will rotate the building in lieu } \\
\text { of changing its glazing area or distribution. Energy } \\
\text { savings are calculated for rotating the building by 90 } \\
\text { degrees, presumably by changing how it sits on the lot } \\
\text { or by building this house plan on a differently oriented } \\
\text { street. We examine only a 90-degree rotation, although } \\
\text { we do include a parametric analysis (discussed below) } \\
\text { of the starting orientation. }\end{array}$ \\
\hline
\end{tabular}

\section{Presentation Format}

Figure 1 shows the simulated annual cooling energy for the baseline home with no westfacing glazing area restriction, and illustrates how all the simulation results will be presented. Note that the simulation output (cooling energy in this case) is plotted against cooling degree-days (CDD) for each of 239 TMY2 climate locations. The red (solid) points represent TMY2 locations within IECC climate zones 1-3, while the blue (open) 
points represent zones 4-8. Graphics showing heating load impacts are plotted against heating degree-days (HDD) rather than CDD.

While Figure 1 shows the energy consumption in absolute terms, most of the graphics that follow will instead show the relative (percent) change in cooling (or heating or total) energy from employing one of the remedies described in Table 1 above. Figure 2 illustrates that presentation by showing the relative change in cooling energy consumption for the Rotate remedy.

Figure 2 again shows results for 239 climate locations. The data represent the relative reductions (percent) in cooling energy consumption resulting from rotating the baseline prototype 90 degrees. The scatterplot shows that percent savings tends to be higher as cooling degree-days get lower, which is possibly indicative of less intense cooling climates having a larger fraction of cooling load attributable to solar gains. 


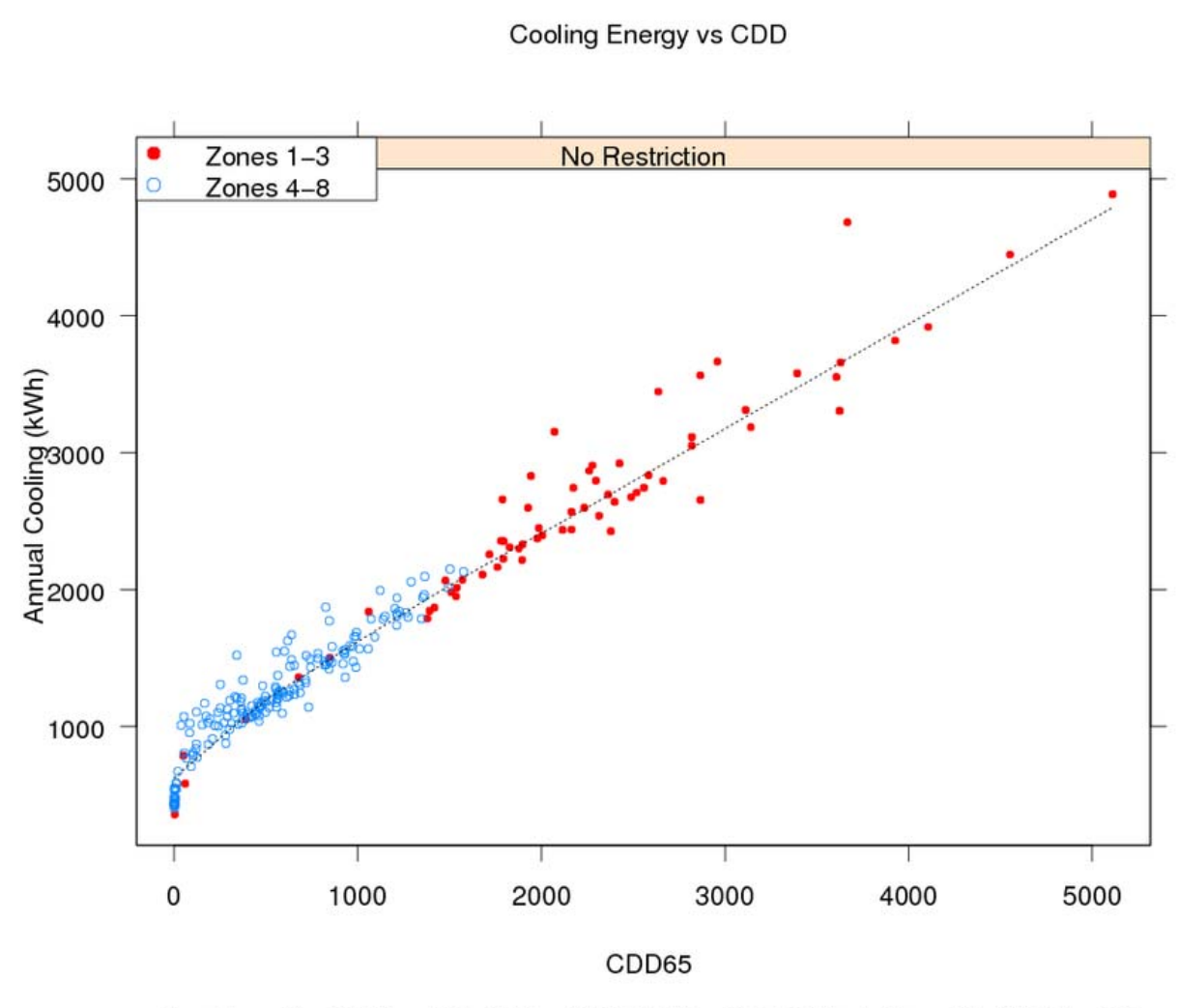

Baseline: $\mathrm{MaxWGA}=110, \mathrm{CFA}=2200, \mathrm{WFR}=0.15$, Orientation $=\mathrm{W}, \mathrm{SHGC}=0.3$

Figure 1: Simulated Cooling Energy Consumption for the Baseline Prototype in 239 TMY2 Locations

This graphic illustrates the presentation of results from 239 TMY2 climate locations. Results are shown for the baseline home with no restriction on west-facing glazing area. This 2200- $\mathrm{ft}^{2}$ home has $132 \mathrm{ft}^{2}$ of west-facing glazing (total glazing area equal to $15 \%$ of floor area, $40 \%$ of which faces due west). 


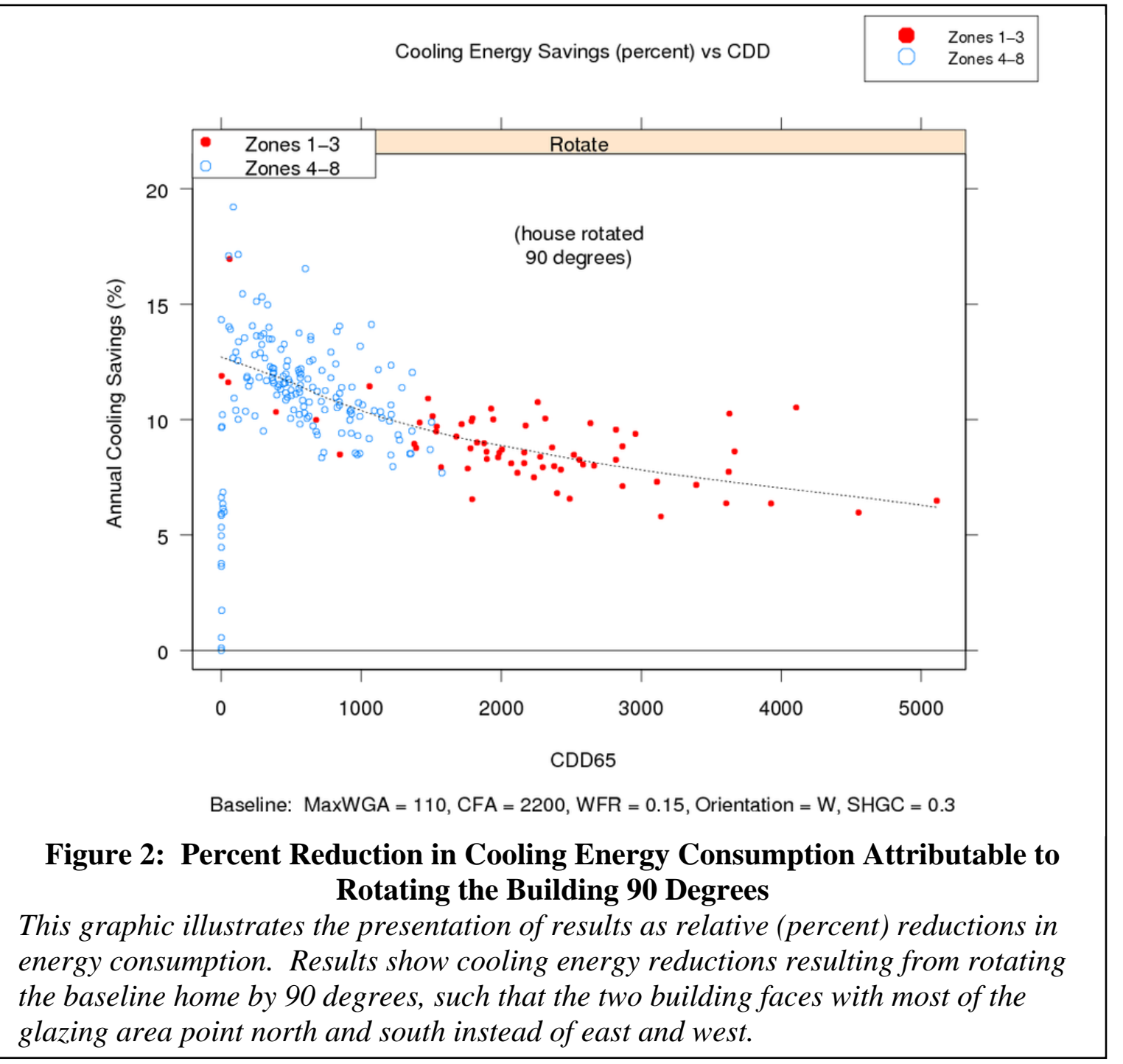

\section{Baseline Results}

The illustrative results in Figure 2 represent only one of the three remedies available to the builder. Hereafter, all graphics will include multiple panels showing the results for all of the remedies listed in Table 2. The percentages shown here are for the baseline home only, with an assumed MaxWGA of $110 \mathrm{ft}^{2}$. In the next section we will show how the savings change as MaxWGA and other house parameters change.

\section{Cooling Energy Savings}

A comparison of the cooling energy savings among all remedies is shown in Figure 3a.

The far right panel repeats the data from Figure 2, while the other panels show savings for the Relocate and Reduce remedies. This figure shows that for the baseline home, rotating the building has the largest impact, with energy savings of 6 to $10 \%$ being 
common, while relocating glazing saves the least, at 1 to $2 \%$. Note that the baseline home has west-facing glazing that is only $22 \mathrm{ft}^{2}$ above the proposed $110-\mathrm{ft}^{2}$ limit. For home designs with larger glazing areas, the cooling energy impacts would be greater.

Although reducing cooling load is the primary objective of this proposed code change, it is important that such reductions do not come at the expense of excessive increases in heating load. The next two sections show how heating load and overall energy cost are impacted by the proposed code change.

\section{Heating Energy Savings}

Figure $3 \mathrm{~b}$ shows the heating load changes corresponding to the cooling load changes. The plotted points represent heating savings resulting from the three remedies. Note that the Relocate and Reduce remedies are always beneficial to the heating load, the former because it puts more glazing on the south face of the building and the latter because it reduces conductive heat losses by reducing overall glazing area. Rotating the building, however, has a detrimental effect on heating load in a few locations. The locations with negative savings are generally limited to southern zones (1-3) with lower heating degreedays, which is not surprising since the warmer the climate, the larger the relative influence of solar gains on heating load.

\section{Energy Cost Savings}

The key question for a given location is whether the beneficial cooling effects shown in Figure 3a are negated by the detrimental heating effects shown in Figure 3b. The answer to that question depends on how heating and cooling are compared. We have chosen to use energy cost as the metric for comparison. Alternatives would be to compare site energy or source energy. We consider source energy to be the most relevant metric, but use energy cost as a reasonable surrogate for source energy because data on fuel prices are easier to obtain than on location-specific source conversion factors. The energy costs here are based on average state fuel prices obtained from the latest revision of the Energy Information Administration's State Energy Data System. ${ }^{4}$ The overall HVAC cost savings results are shown in Figure 3c.

Clearly, with only a few exceptions, the proposed code change would result in a net benefit to homes in all climates. The very few exceptions are locations in lowernumbered zones (1-3) that also have low CDD values. These are typically locations in Marine zone 3 (the California coast). The net cost reductions are in the 1 to $2 \%$ range for the Relocate remedy, 2 to $4 \%$ for the Reduce remedy, and 3 to $8 \%$ for the Rotate remedy.

Figures 3a through 3c represent the fundamental technical defense of the proposed code change, showing that, although the benefit varies with the approach to achieving compliance, the proposed change would virtually always result in a net benefit to the homeowner in terms of energy costs. That is, for an average home, the proposed code change has no detrimental impacts and offers little or no risk of giving builders perverse

\footnotetext{
${ }^{4}$ http://www.eia.doe.gov/emeu/states/_seds.html
} 
incentives. The following section presents a parametric analysis conducted to verify that these advantageous characteristics hold for buildings that depart from the baseline (average) home. 


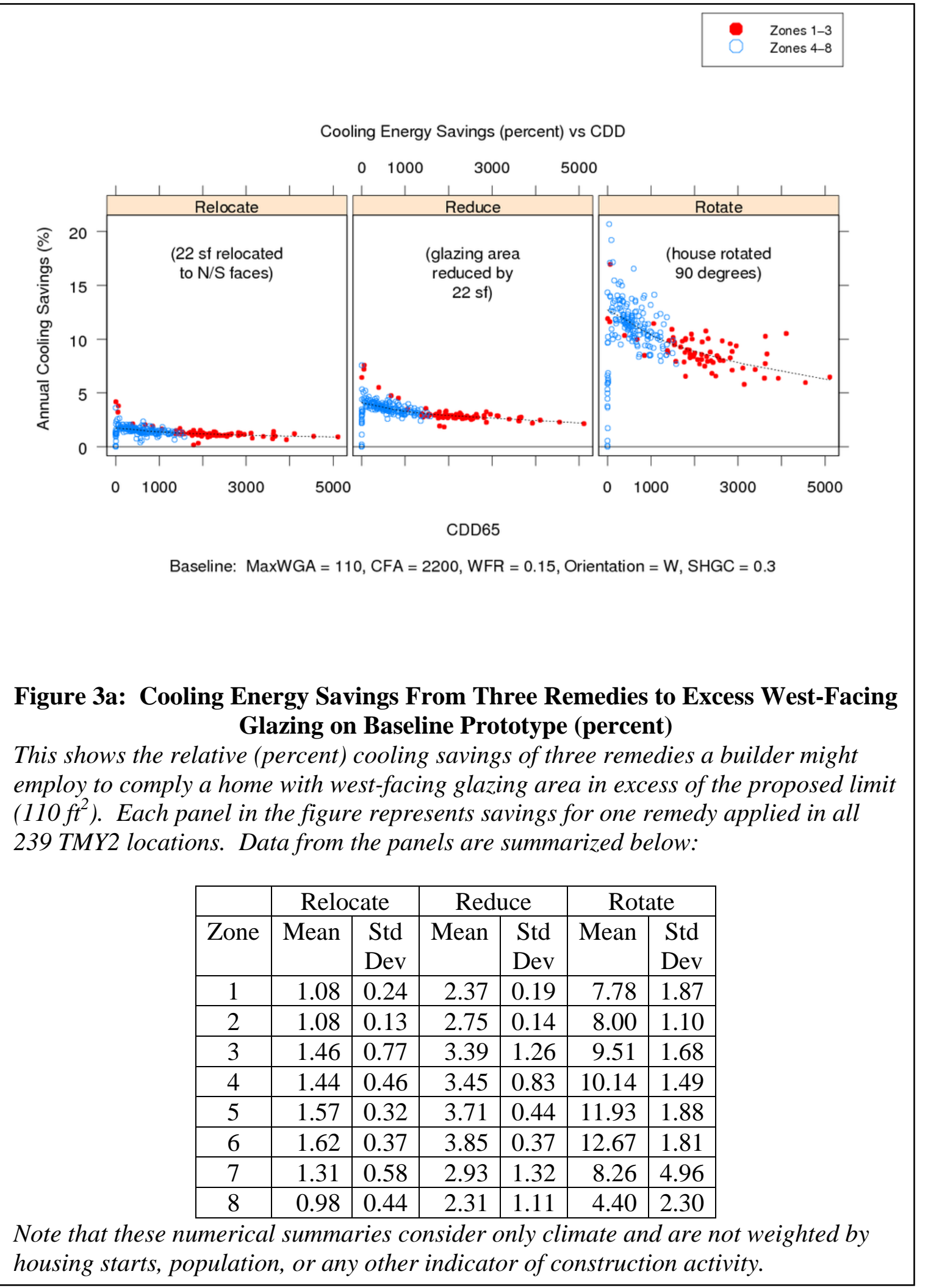




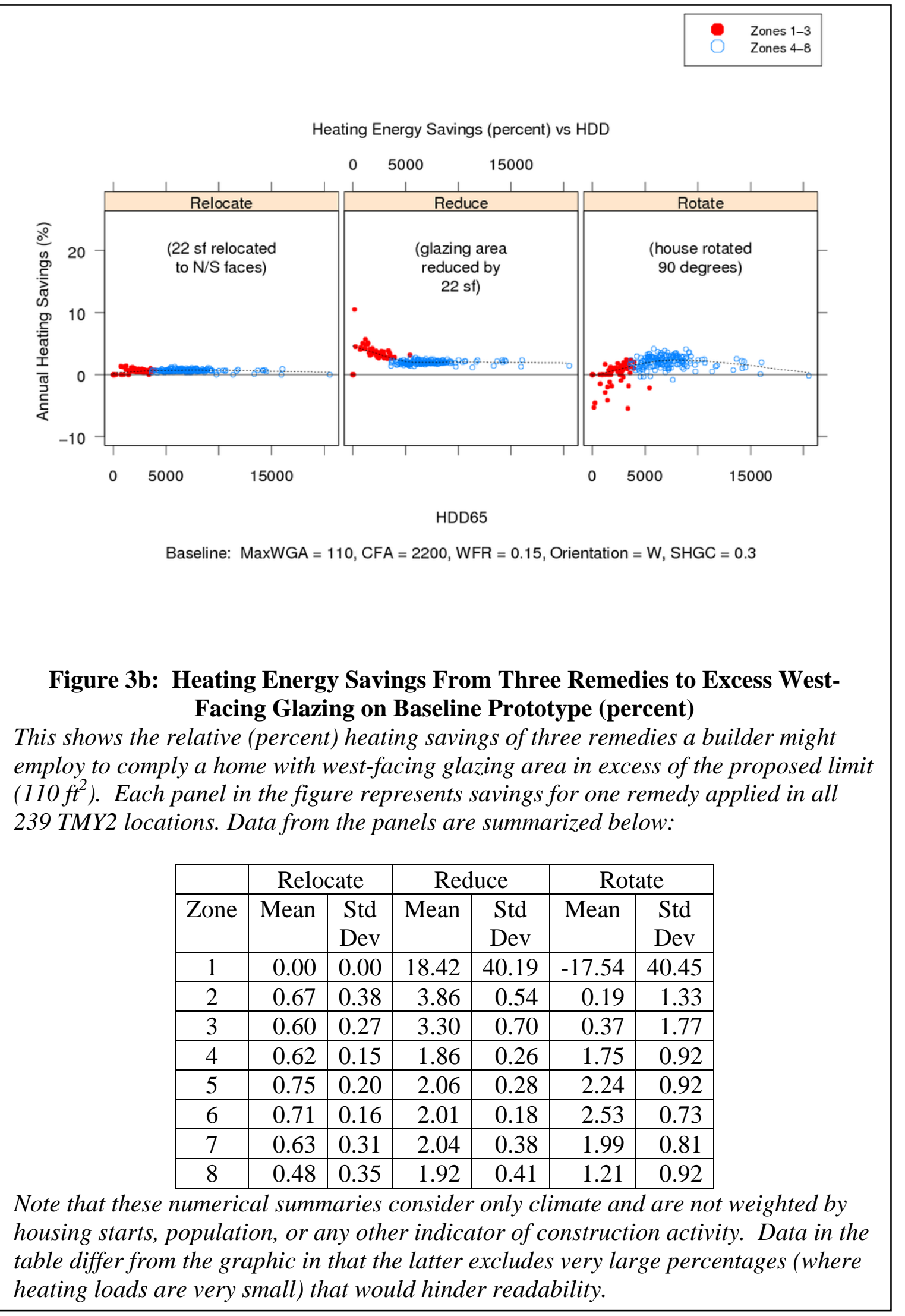




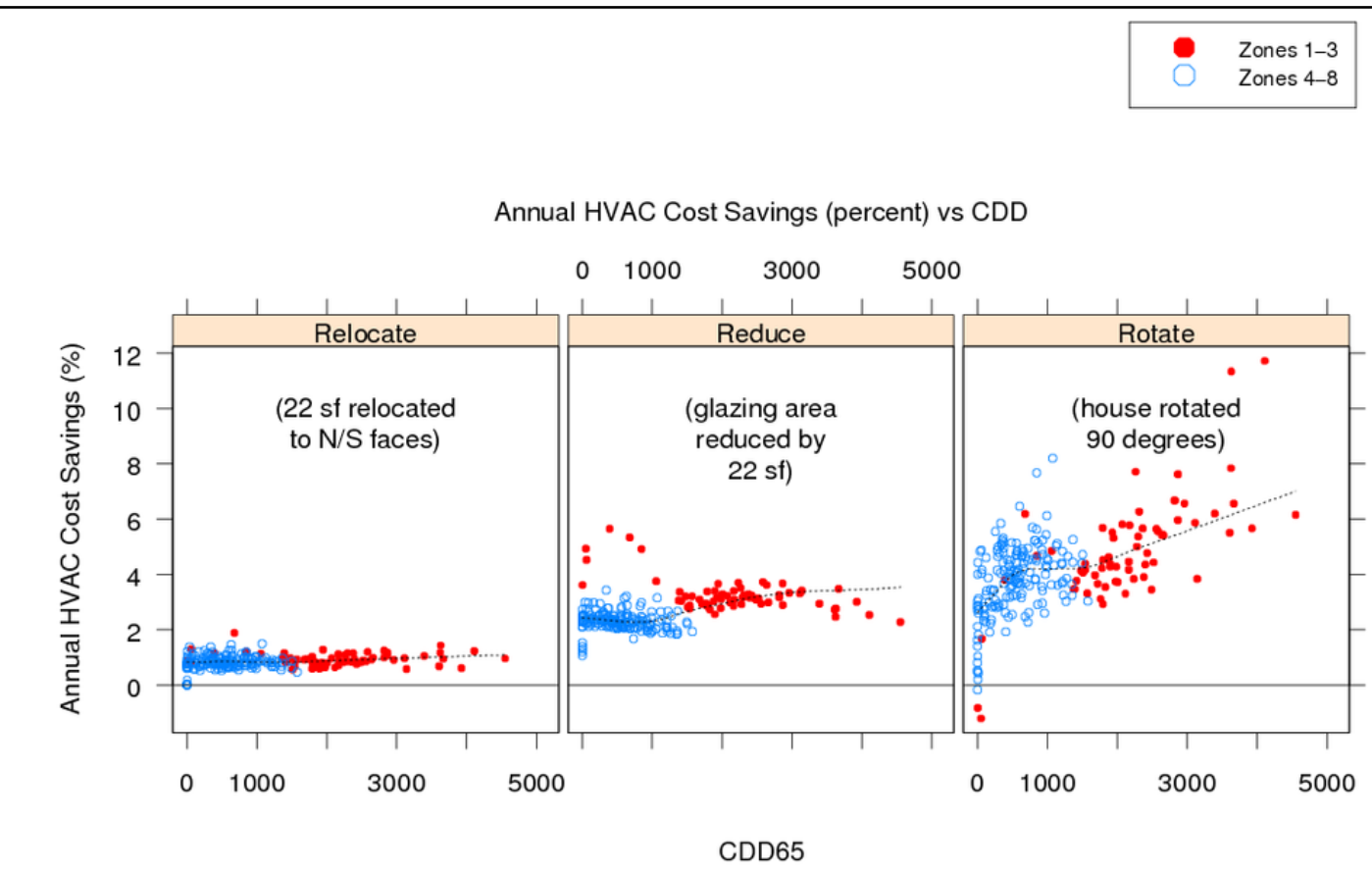

Baseline: MaxWGA $=110, \mathrm{CFA}=2200, \mathrm{WFR}=0.15$, Orientation $=\mathrm{W}, \mathrm{SHGC}=0.3$

Figure 3c: HVAC Cost Savings From Three Remedies to Excess West-Facing Glazing on Baseline Prototype (percent)

This shows the relative (percent) energy cost savings of three remedies a builder might employ to comply a home with west-facing glazing area in excess of the proposed limit $\left(110 \mathrm{ft}^{2}\right)$. Each panel in the figure represents cost savings for one remedy applied in all 239 TMY2 locations. Data from the panels are summarized below:

\begin{tabular}{|c|c|c|c|c|c|c|}
\hline & \multicolumn{2}{|c|}{ Relocate } & \multicolumn{2}{c|}{ Reduce } & \multicolumn{2}{c|}{ Rotate } \\
\hline Zone & Mean & $\begin{array}{c}\text { Std } \\
\text { Dev }\end{array}$ & Mean & $\begin{array}{c}\text { Std } \\
\text { Dev }\end{array}$ & Mean & $\begin{array}{c}\text { Std } \\
\text { Dev }\end{array}$ \\
\hline 1 & 1.10 & 0.28 & 2.66 & 0.28 & 8.39 & 2.57 \\
\hline 2 & 0.93 & 0.16 & 3.25 & 0.25 & 5.24 & 1.02 \\
\hline 3 & 0.92 & 0.25 & 3.37 & 0.73 & 4.14 & 1.65 \\
\hline 4 & 0.78 & 0.15 & 2.22 & 0.28 & 3.63 & 1.11 \\
\hline 5 & 0.91 & 0.22 & 2.43 & 0.34 & 4.28 & 1.20 \\
\hline 6 & 0.84 & 0.16 & 2.32 & 0.20 & 4.14 & 0.77 \\
\hline 7 & 0.72 & 0.34 & 2.20 & 0.49 & 2.84 & 1.25 \\
\hline 8 & 0.54 & 0.37 & 2.02 & 0.48 & 1.60 & 1.12 \\
\hline
\end{tabular}

Note that these numerical summaries consider only climate and are not weighted by housing starts, population, or any other indicator of construction activity. 


\section{Parametric Energy Analysis}

The previous section showed that the proposed code change is almost universally beneficial (lowers overall energy costs) for an average home in any U.S. climate. This section evaluates buildings that depart from average. Table 3 shows the parameters that are varied in this analysis. As each parameter is varied, the other parameters are held at their baseline values in the DOE-2 simulations.

\begin{tabular}{|c|c|}
\hline \multicolumn{2}{|c|}{$\begin{array}{c}\text { Table 3: Summary of Parameters Subjected to Parametric Analysis } \\
\text { These five major simulation assumptions were each varied independently of the others } \\
\text { to assess the sensitivity of energy savings results to buildings of various size and } \\
\text { configuration. }\end{array}$} \\
\hline Parameter & Parametric Analysis Scheme \\
\hline $\begin{array}{l}\text { Maximum Allowable West-Facing } \\
\text { Glazing Area (MaxWGA) }\end{array}$ & 90 to $150 \mathrm{ft}^{2}$ \\
\hline Conditioned Floor Area (CFA) & 1500 to $5000 \mathrm{ft}^{2}$ \\
\hline Window-Floor Ratio (WFR) & 12 to $25 \%$ \\
\hline Glazing SHGC & 0.2 to 0.5 \\
\hline Actual "west" orientation & Due west \pm 45 degrees (SW to NW) \\
\hline
\end{tabular}

\section{Parameter: Maximum Allowable West-Facing Glazing Area (MaxWGA, $\mathrm{ft}^{2}$ )}

We chose a MaxWGA of $110 \mathrm{ft}^{2}$ as a reasonable value that accomplishes the various goals of this work - reducing energy consumption; encouraging builders to think about home orientation and lot layout; accommodating builders' genuine concerns regarding lot layout restrictions; etc. This parametric analysis shows how the energy savings would change with lower (more stringent) and higher MaxWGA values.

\section{Cooling Energy Savings}

Figure 6a shows how cooling energy savings vary with changes in MaxWGA. Each panel represents 239 DOE-2 simulations. The three rows of panels correspond to the three remedies discussed earlier. Each column of panels shows the results for a single level of MaxWGA, with the second column showing the baseline value of $110 \mathrm{ft}^{2}$.

The format of these results will be used to display all the parametric analyses. A few observations that are helpful in understanding the format are given below. Note that these are based on parametrics relative to a baseline prototype having $2200 \mathrm{ft}^{2}$ of conditioned floor area, total glazing area equal to $15 \%$ of the floor area, and west-facing glazing area equal to $40 \%$ of total glazing area: $2200 \times 0.15 \times 0.40=132 \mathrm{ft}^{2}$ of westfacing glazing. 
- As the code-specified limit on west-facing glazing (MaxWGA) decreases, the amount of west-facing glazing that must be relocated or removed increases and, consequently, the energy impact increases for the Relocate and Remove remedies.

- The energy impact of the Rotate remedy is the same regardless of the MaxWGA (until MaxWGA exceeds the amount of west-facing glazing of a proposed home; see next bullet).

- If a proposed home already has less west-facing glazing area than the code's mandated maximum (MaxWGA), the energy impact becomes zero for all remedies. This is illustrated by the rightmost column of panels, for which there is not need to apply any remedy (the prototype's west-facing glazing area is $132 \mathrm{ft}^{2}$, which is less than a MaxWGA of $150 \mathrm{ft}^{2}$ ).

\section{Heating Energy Savings}

Figure $6 \mathrm{~b}$ shows how heating energy savings vary with changes in MaxWGA. Again, each panel represents 239 DOE-2 simulations, the three rows of panels correspond to the three remedies, and each column shows the results for a single level of MaxWGA. There are few surprises in these results. As with the cooling load, a lower MaxWGA results in greater impact on heating. Further, only the magnitude of the impact seems to change; the sense is never reversed.

\section{Energy Cost Savings}

Figure 6c shows the final and most important metric - energy cost savings. This, of course, combines the cooling and heating effects, weighting each by its respective fuel price. As with heating and cooling, the total relative savings increases as MaxWGA decreases. Because the glazing amounts involved $\left(0\right.$ to $\left.42 \mathrm{ft}^{2}\right)$ are relatively small, the relationship between MaxWGA and cost impact is more or less linear. 


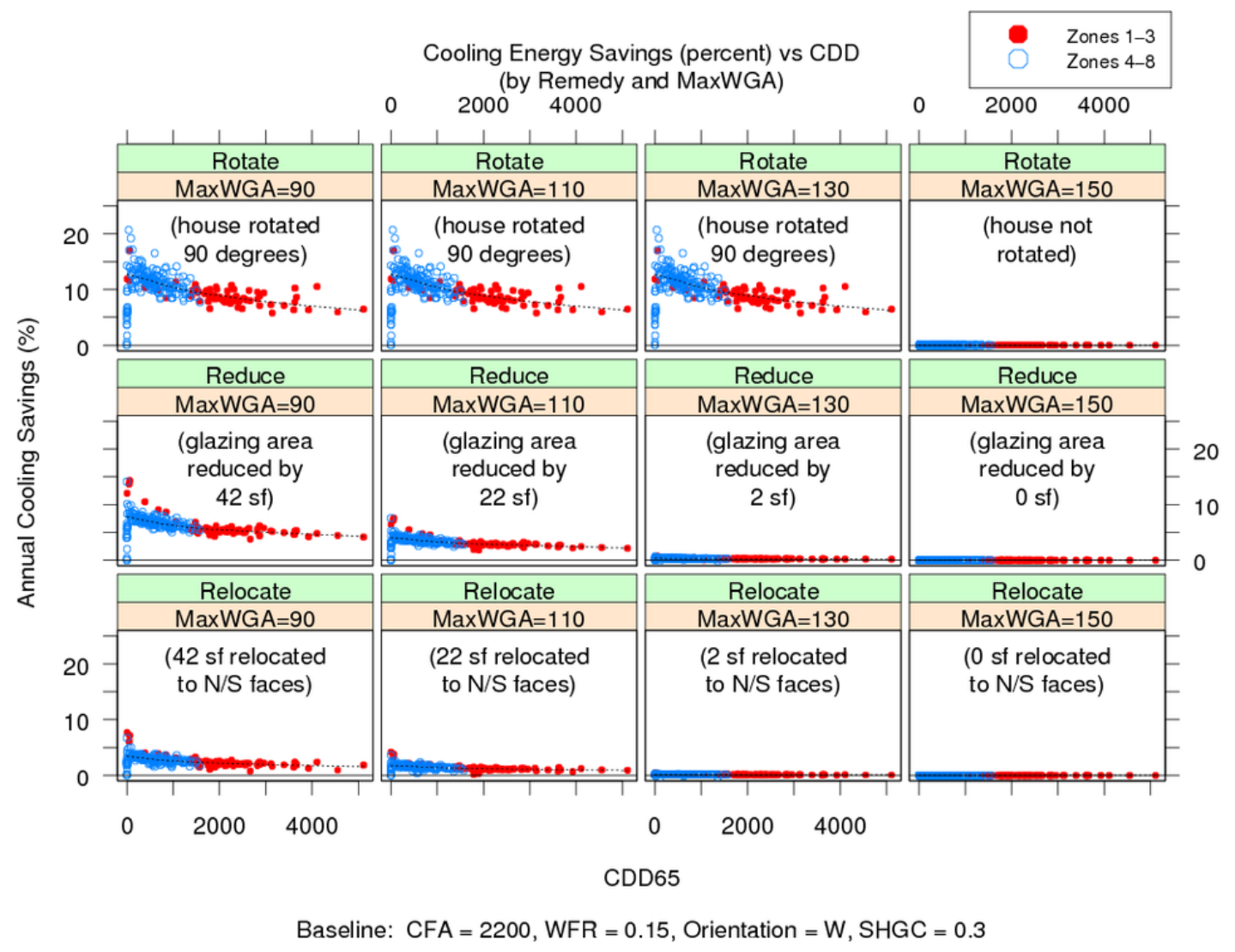

Figure 6a: Parametric Analysis of Maximum West-Facing Glazing AreaCooling Energy Savings (percent)

Each panel shows 239 DOE-2 simulations. The three rows correspond to the three remedies builders might employ to bring a home into compliance. The four columns represent four values of MaxWGA. Column $2\left(110 \mathrm{ft}^{2}\right)$ is the baseline. 


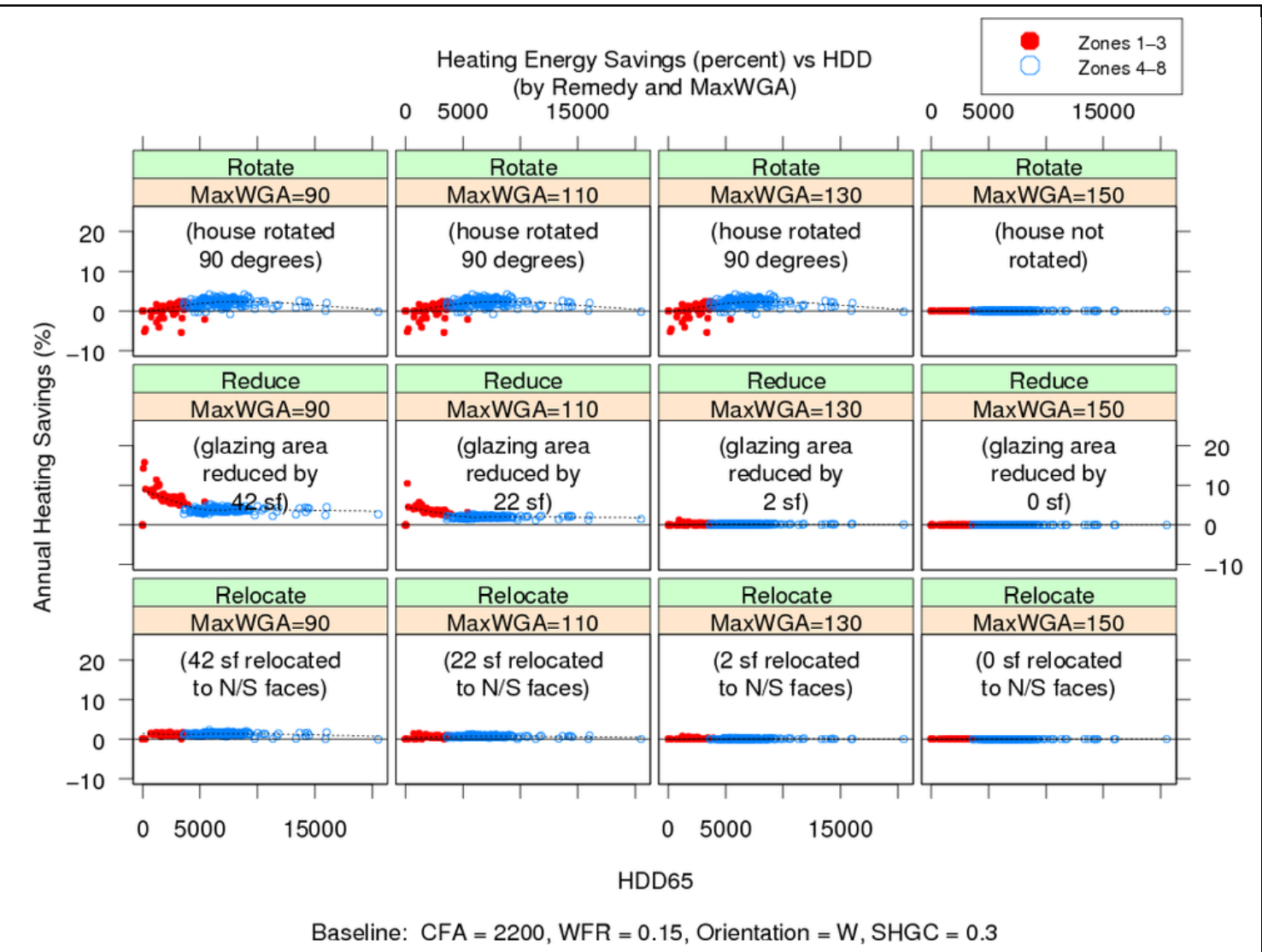

Figure 6b: Parametric Analysis of Maximum West-Facing Glazing AreaHeating Energy Savings (percent)

Each panel shows 239 DOE-2 simulations. The three rows correspond to the three remedies builders might employ to bring a home into compliance. The four columns represent four values of MaxWGA. Column $2\left(110 \mathrm{ft}^{2}\right)$ is the baseline. 


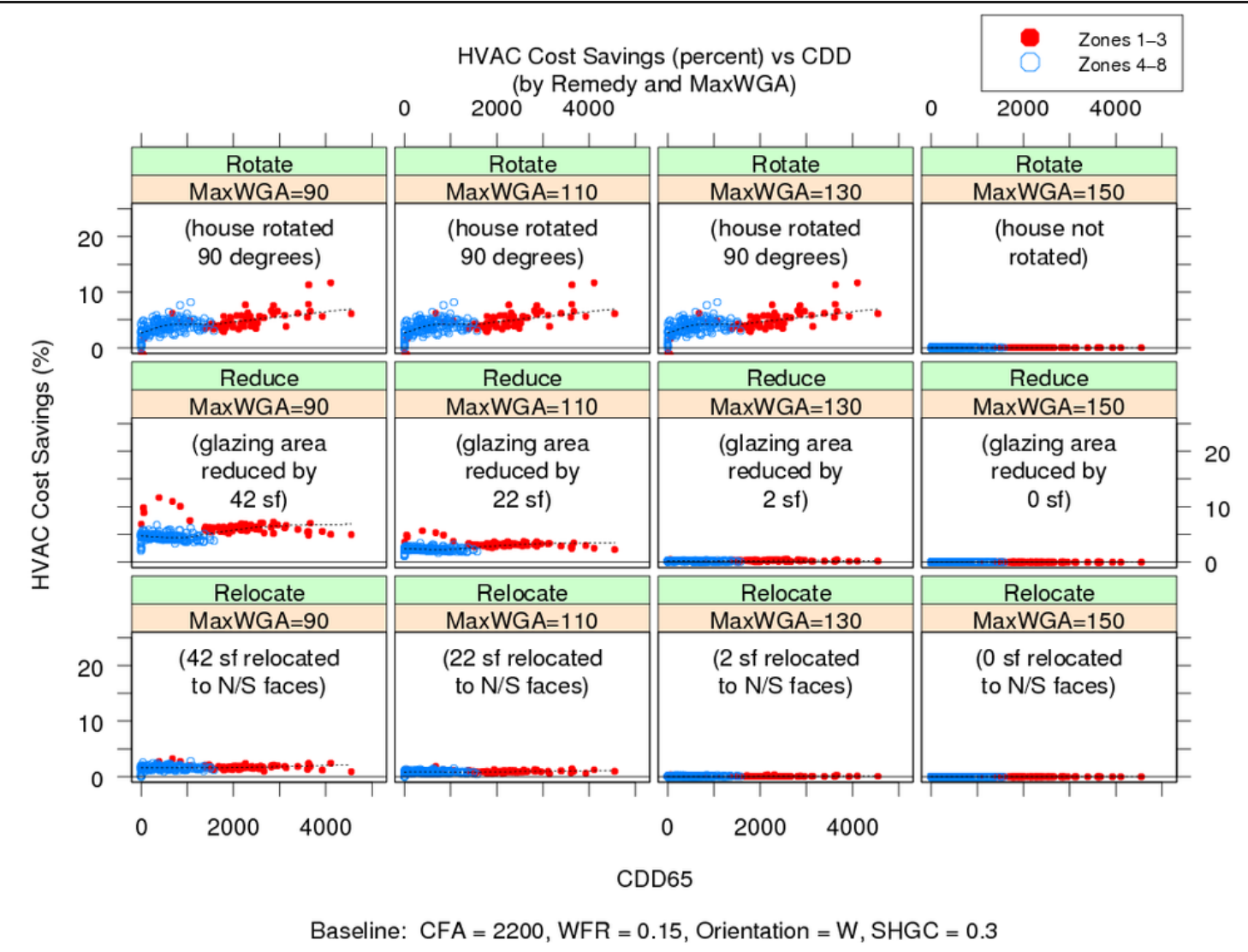

Figure 6c: Parametric Analysis of Maximum West-Facing Glazing AreaEnergy Cost Savings (percent)

Each panel shows 239 DOE-2 simulations. The three rows correspond to the three remedies builders might employ to bring a home into compliance. The four columns represent four values of MaxWGA. Column $2\left(110 \mathrm{ft}^{2}\right)$ is the baseline. 


\section{Parameter: Conditioned Floor Area (CFA, $\mathrm{ft}^{2}$ )}

Conditioned Floor Area (CFA) is an important parameter in this analysis because the proposed code change specifies its MaxWGA in terms of absolute west-facing glazing area, not as a percentage of floor area. As discussed earlier, this absolute area approach will impose a greater restriction on large buildings than on small ones, at least to the extent that total glazing area as a percentage of floor area tends to be similar across building sizes. Our parametric analysis evaluates CFA values ranging from $1500 \mathrm{ft}^{2}$ to $5000 \mathrm{ft}^{2}$.

\section{Cooling Energy Savings}

Figure 7a shows the cooling impact of varying CFA. In all panels, the MaxWGA is the same, $110 \mathrm{ft}^{2}$. Because is the window-floor ratio (WFR) is also constant, at $15 \%$, and an increase in CFA increases the amount of glazing that must be relocated or removed. The cooling energy impact increases accordingly. For the Relocate and Reduce remedies, the energy impact increases substantially with CFA. The Rotate remedy, however, shows only minor increases in impact, reflective of the fact that the primary difference between small and large homes is the fraction of the cooling load that is attributable to solar gains.

The leftmost column, for which CFA equals $1500 \mathrm{ft}^{2}$, illustrates a key characteristic of the proposed code change: many small homes will be completely unaffected by the westfacing glazing area limit. In this case, the $1500-\mathrm{ft}^{2}$ home with total glazing area equal to $15 \%$ of floor area and west-facing glazing area equal to $40 \%$ of the total glazing, has $1500 \times 0.15 \times 0.40=90 \mathrm{ft}^{2}$ of west-facing glazing-well below the $110-\mathrm{ft}^{2}$ limit and, therefore, not in need of any remedy.

\section{Heating Energy Savings}

The sensitivity of heating energy savings to changes in CFA is shown in Figure 7b. As with cooling, increasing CFA results in substantial increases in heating energy savings for the Relocate and Reduce remedies, while the Rotate remedy is largely insensitive to CFA. Heating energy savings from reductions in west-facing glazing are particularly significant, especially in high cooling climates.

\section{Energy Cost Savings}

Figure 7c shows the sensitivity of overall energy cost savings to changes in CFA. The same basic patterns noticed in cooling and heating energy savings are evident here as well. Notably, virtually all locations see net energy cost benefits regardless of CFA, even where heating energy was impacted detrimentally. 


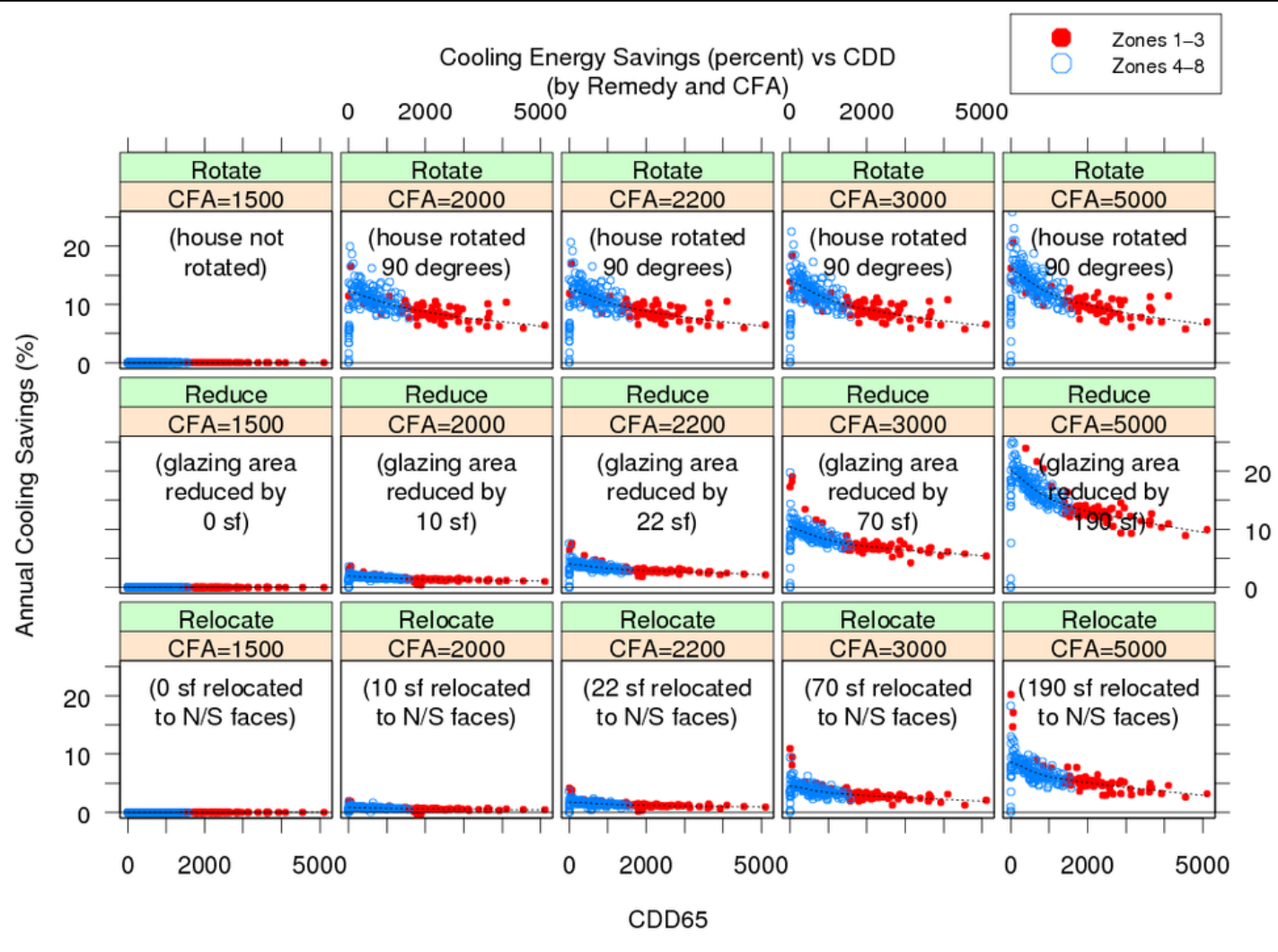

Baseline: MaxWGA $=110, \mathrm{WFR}=0.15$, Orientation $=\mathrm{W}, \mathrm{SHGC}=0.3$

Figure 7a: Parametric Analysis of Conditioned Floor Area-Cooling Energy Savings (percent)

Each panel shows 239 DOE-2 simulations. The three rows correspond to the three remedies builders might employ to bring a home into compliance. The five columns represent five values of CFA. Column $3\left(2200 \mathrm{ft}^{2}\right)$ is the baseline. 


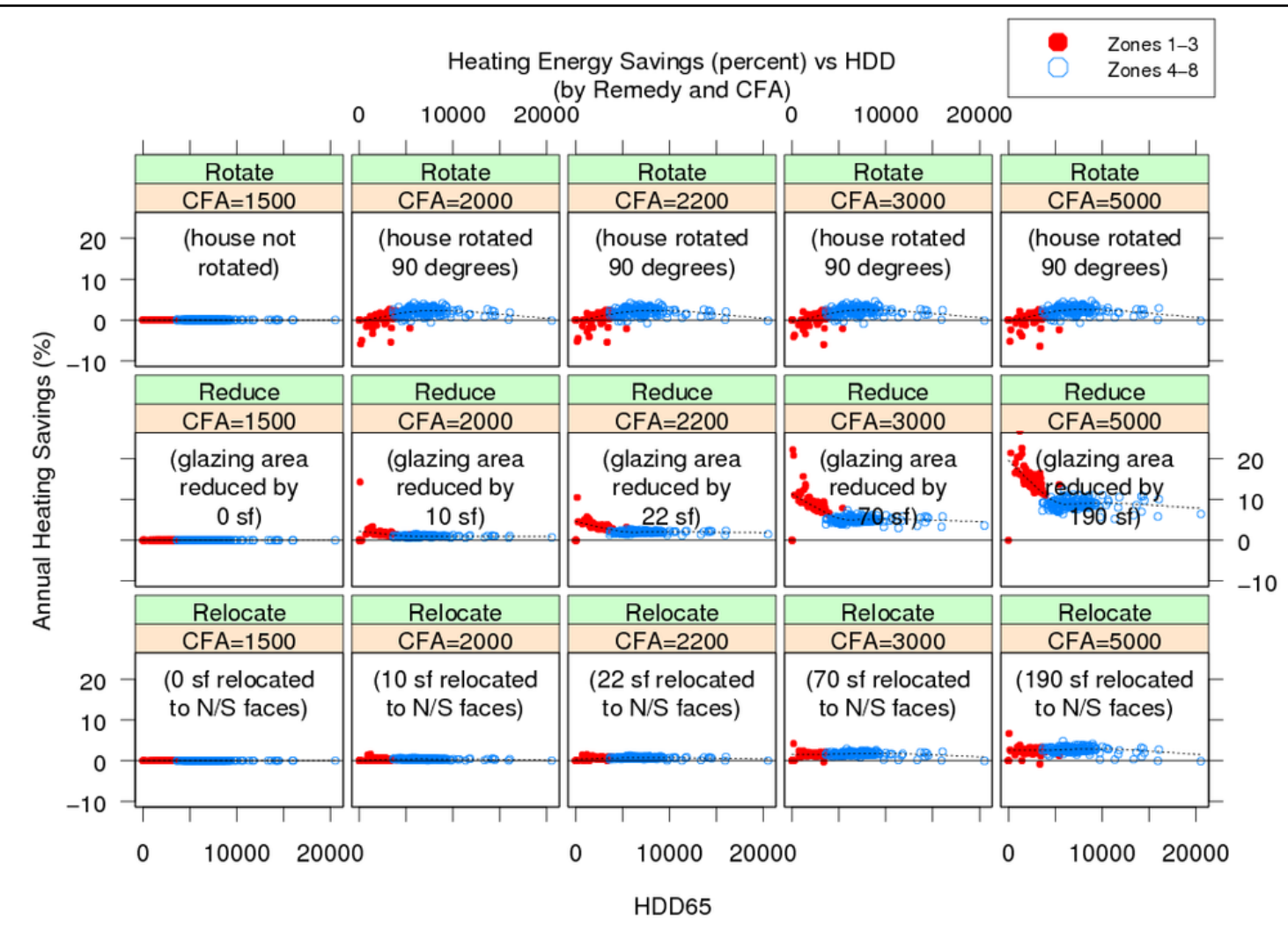

Baseline: $M a x W G A=110, W F R=0.15$, Orientation $=W, S H G C=0.3$

Figure 7b: Parametric Analysis of Conditioned Floor Area-Heating Energy Savings (percent)

Each panel shows 239 DOE-2 simulations. The three rows correspond to the three remedies builders might employ to bring a home into compliance. The five columns represent five values of CFA. Column $3\left(2200 \mathrm{ft}^{2}\right)$ is the baseline. 


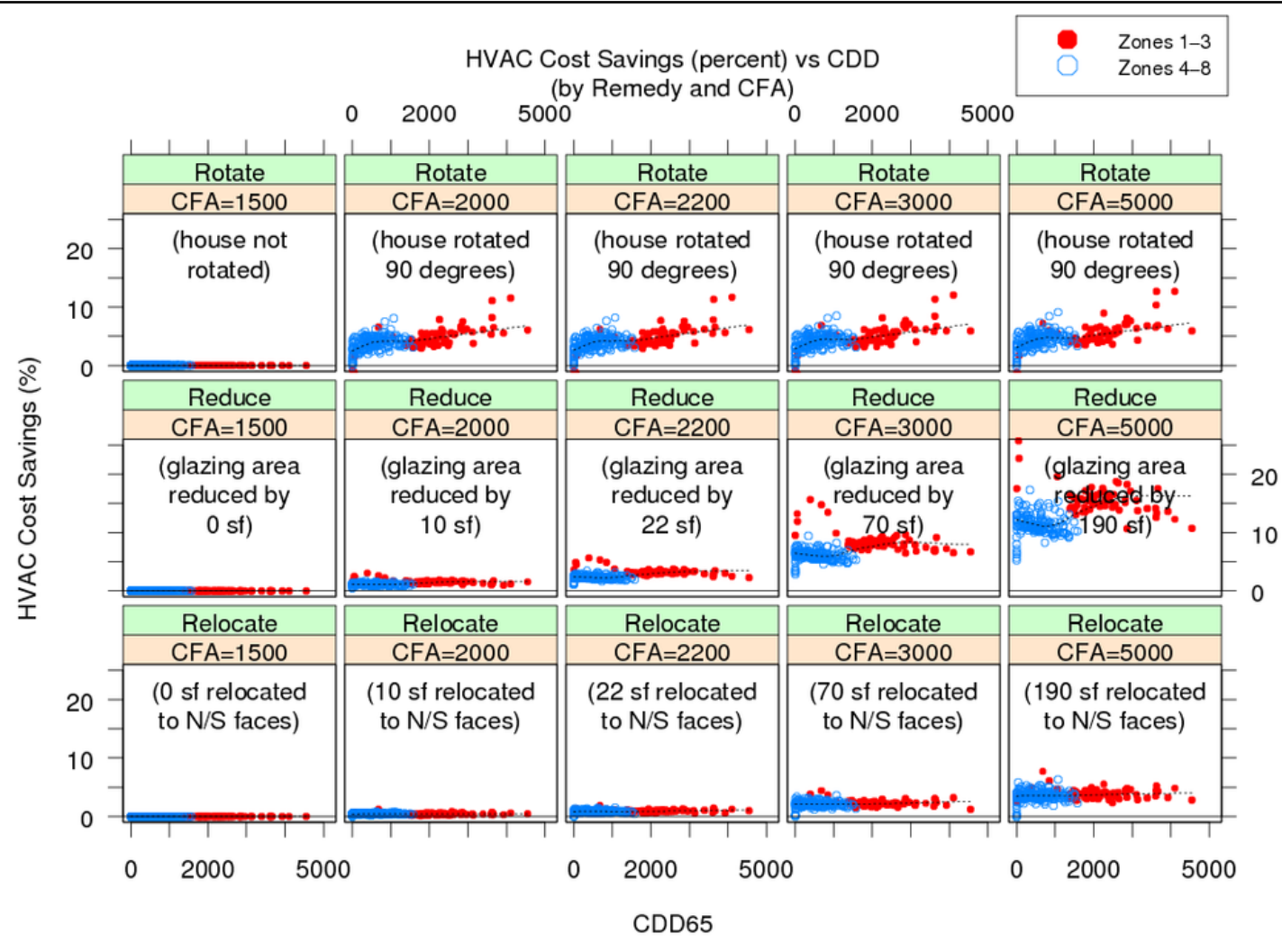

Baseline: $M a x W G A=110, W F R=0.15$, Orientation $=W, S H G C=0.3$

Figure 7c: Parametric Analysis of Conditioned Floor Area-Energy Cost Savings (percent)

Each panel shows 239 DOE-2 simulations. The three rows correspond to the three remedies builders might employ to bring a home into compliance. The five columns represent five values of CFA. Column $3\left(2200 \mathrm{ft}^{2}\right)$ is the baseline. 


\section{Parameter: Window-Floor Ratio (WFR, p.u.)}

The baseline window-floor ratio (WFR) of $15 \%$ (0.15 per unit) was selected because it is near the average WFR encountered across the U.S. The parametric analysis of WFR levels ranges from $12 \%$, which is closer to an average value for far northern climates, to $25 \%$ which, although well above average, is common in some places, especially in larger and higher-end homes.

\section{Cooling Energy Savings}

Figure 8a shows the relationship between WFR and cooling energy savings for the proposed code change. Once again, the nature of the absolute area restriction is evident in the leftmost column of panels. The baseline $2200-\mathrm{ft}^{2}$ house with $12 \%$ WFR and $40 \%$ of the glazing on the west face has $2200 \times 0.12 \times 0.40=105.6 \mathrm{ft}^{2}$ of west-facing glazing, less than the MaxWGA of $100 \mathrm{ft}^{2}$, and consequently not requiring any remedy to achieve compliance. The familiar pattern of progressively higher relative savings with higher WFR is evident for the Relocate and Reduce remedies, as is the roughly constant savings for the Rotate remedy.

\section{Heating Energy Savings}

The sensitivity of heating energy savings to WFR is shown in Figure 8c. Patterns are similar to those of the cooling energy parametrics. Also, as is typically the case for the Rotate remedy, there are detrimental impacts on heating load in some cooling-dominated climates.

\section{Energy Cost Savings}

Figure 8c shows the sensitivity of overall energy cost savings to WFR. As is the case with the other parameters analyzed, the net (heating plus cooling) savings is always positive, regardless of WFR, except when the home's west-facing glazing area is below the MaxWGA of $110 \mathrm{ft}^{2}$, in which case there is no impact at all. 


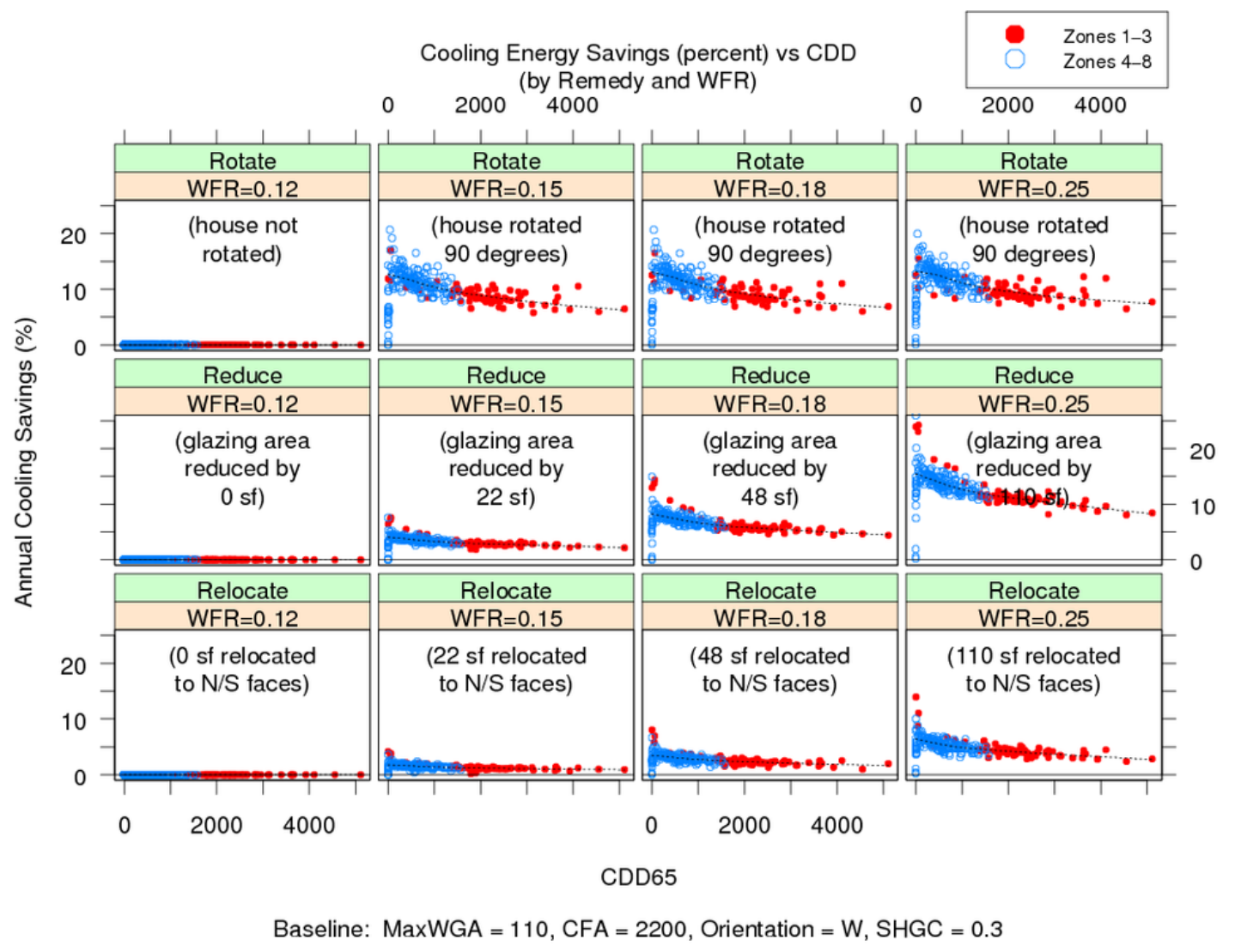

Figure 8a: Parametric Analysis of Window-Floor Ratio-Cooling Energy Savings (percent)

Each panel shows 239 DOE-2 simulations. The three rows correspond to the three remedies builders might employ to bring a home into compliance. The four columns represent four values of WFR. Column $2(0.15$ or $15 \%)$ is the baseline. 


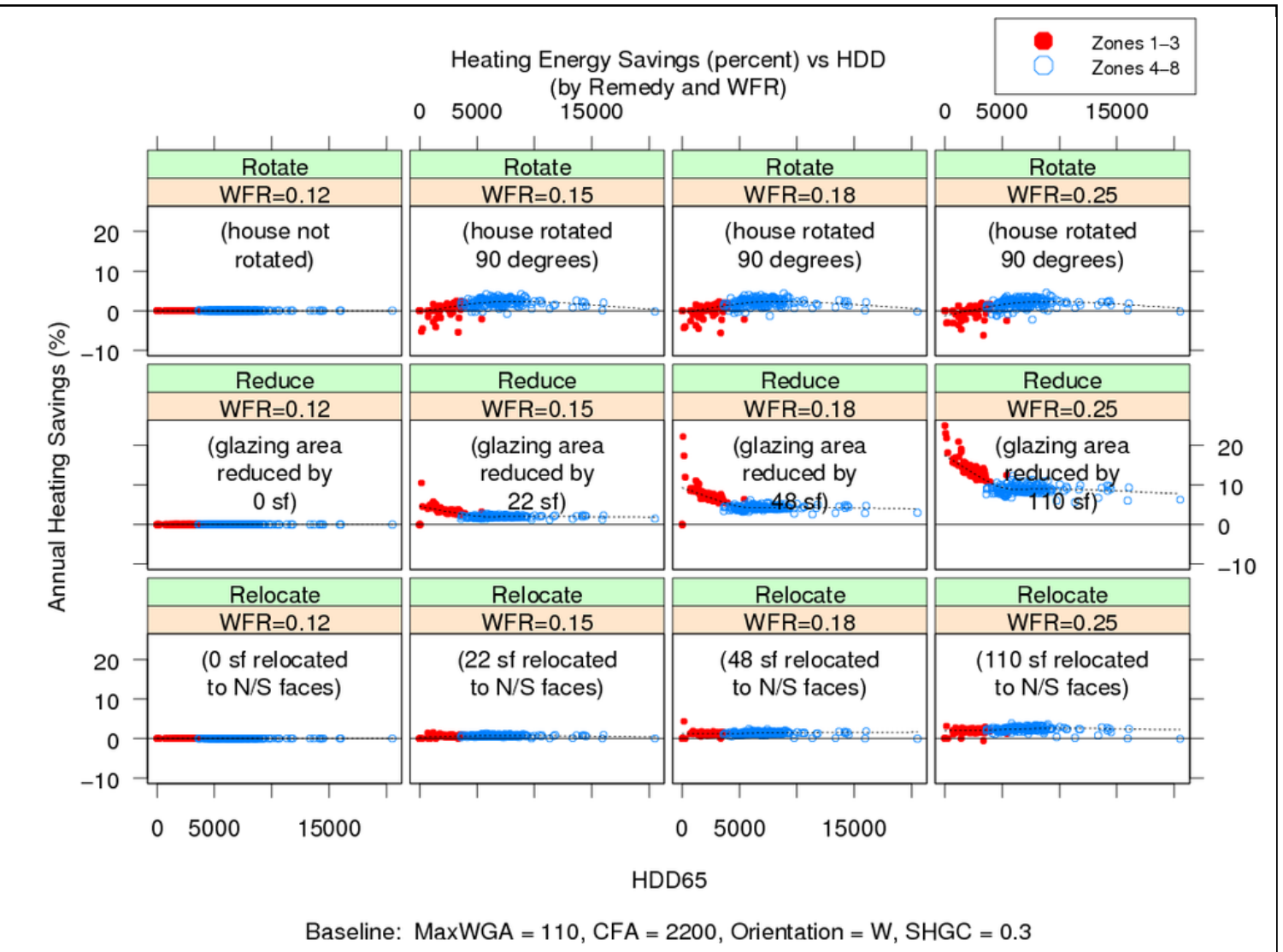

Figure 8b: Parametric Analysis of Window-Floor Ratio-Heating Energy Savings (percent)

Each panel shows 239 DOE-2 simulations. The three rows correspond to the three remedies builders might employ to bring a home into compliance. The four columns represent four values of WFR. Column $2(0.15$ or $15 \%)$ is the baseline. 


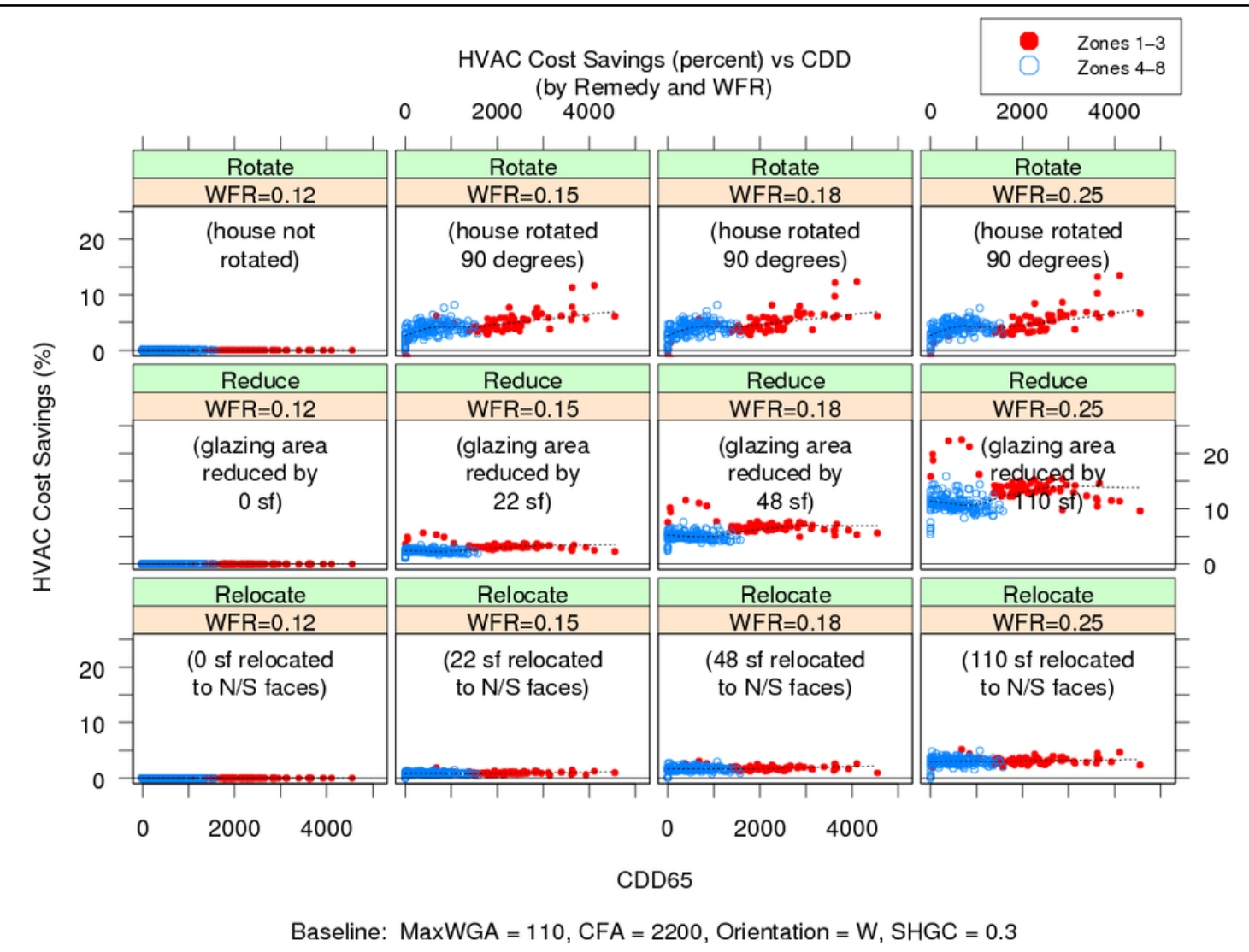

Figure 8c: Parametric Analysis of Window-Floor Ratio-Energy Cost Savings (percent)

Each panel shows 239 DOE-2 simulations. The three rows correspond to the three remedies builders might employ to bring a home into compliance. The four columns represent four values of WFR. Column $2(0.15$ or $15 \%)$ is the baseline. 


\section{Parameter: Orientation of Home (Orientation, compass designation)}

This proposed code change is designed to discourage homes with high west-facing glazing area. A key consideration is how the code defines "west facing." The proposed limit on west-facing glazing will be of very limited impact if it is restricted to a too-small band of orientations around due west, and can have negative impacts if it extends to a too-large range.

A parametric analysis of the home's orientation was conducted to identify appropriate bounds on the proposed glazing area restriction. By analyzing the energy savings of the three remedies for a range of initial orientations, we can identify the orientation band within which the code change always has a beneficial impact on overall energy consumption and avoids perverse incentives to the builder. We evaluate initial building orientations between southwest (SW, 225 degrees) and northwest (NW, 315 degrees), computing the energy savings of relocating or reducing glazing on the westward face or rotating the building 90 degrees from the initial orientation. The orientation labels on the graphs refer to the direction the wall with the greatest glazing area faces. The meanings are discussed in Table 4.

Table 4: Azimuths Evaluated in Parametric Analysis of Initial Orientation

\begin{tabular}{|c|c|l|}
\hline Graph Label & $\begin{array}{c}\text { Azimuth } \\
\text { (degrees) }\end{array}$ & \multicolumn{1}{c|}{ Description } \\
\hline SW & 225 & Forty-five degrees south of due west. \\
\hline WSW & 240 & $\begin{array}{l}\text { Thirty degrees south of due west. Note that this is not } \\
\text { halfway between W and SW (which would be 22.5 degrees } \\
\text { south of west), but is closer to SW. }\end{array}$ \\
\hline W & 270 & This is due west. $^{5}$ \\
\hline WNW & 300 & $\begin{array}{l}\text { Thirty degrees north of due west. Note that this is not } \\
\text { halfway between W and NW (which would be 22.5 degrees } \\
\text { north of west), but is closer to NW. }\end{array}$ \\
\hline NW & 315 & Forty-five degrees north of due west. \\
\hline
\end{tabular}

Recall that our prototype home is symmetrical. This means, for example, that a home with an initial orientation of southwest would have the same glazing area facing southwest and northeast. After rotating, the same building would have high-glazing walls facing northwest and southeast.

\section{Cooling Energy Savings}

Figure 9a shows the sensitivity of cooling energy savings to changes in the initial orientation of a home. The five columns show results for five azimuths between

\footnotetext{
${ }^{5}$ Note that all orientations and compass readings used here refer to "true" directions, not compass directions. Compass readings in any location must be adjusted for the local magnetic declination to obtain true readings. See http://www.ngdc.noaa.gov/geomag/declination.shtml for additional information.
} 
southwest and northwest (see definitions in Table 4). The center column represents true west, with columns to the left indicating directions south of west and columns to the right representing directions north of west. The proposed code change shows the greatest benefit for homes facing due west, with cooling energy savings diminishing as the home orientation deviates from due west. At the NW (315 degrees) azimuth, cooling energy savings go negative for the Relocate and Rotate remedies, suggesting that imposing a glazing area restriction on walls facing that far north may not be advantageous.

\section{Heating Energy Savings}

Figure 9b shows the sensitivity of heating energy savings to changes in the initial orientation of a home. The five columns show results for five azimuths between southwest and northwest (see definitions in Table 4). The center column represents true west, with columns to the left indicating directions south of west and columns to the right representing directions north of west. The proposed code change shows heating savings for all remedies and all orientations except for rotation of homes with high glazing facing west and north of west. Recall that the prototype has the same glazing area facing eastwardly as westwardly, so rotating the west-facing glazing away from west also moves the east-facing glass away from east, which eliminates some beneficial solar heating.

\section{Energy Cost Savings}

Figure 9c shows the sensitivity of overall energy cost savings to changes in the initial orientation of a home. The five columns show results for five azimuths between southwest and northwest (see definitions in Table 4). The center column represents true west, with columns to the left indicating directions south of west and columns to the right representing directions north of west. The proposed code change generally shows benefit, or at least no detriment, for homes between 45 degrees south of west to 30 degrees north of west. This suggests that the proposed code change should limit its definition of "west" to that range when restricting west-facing glazing. 


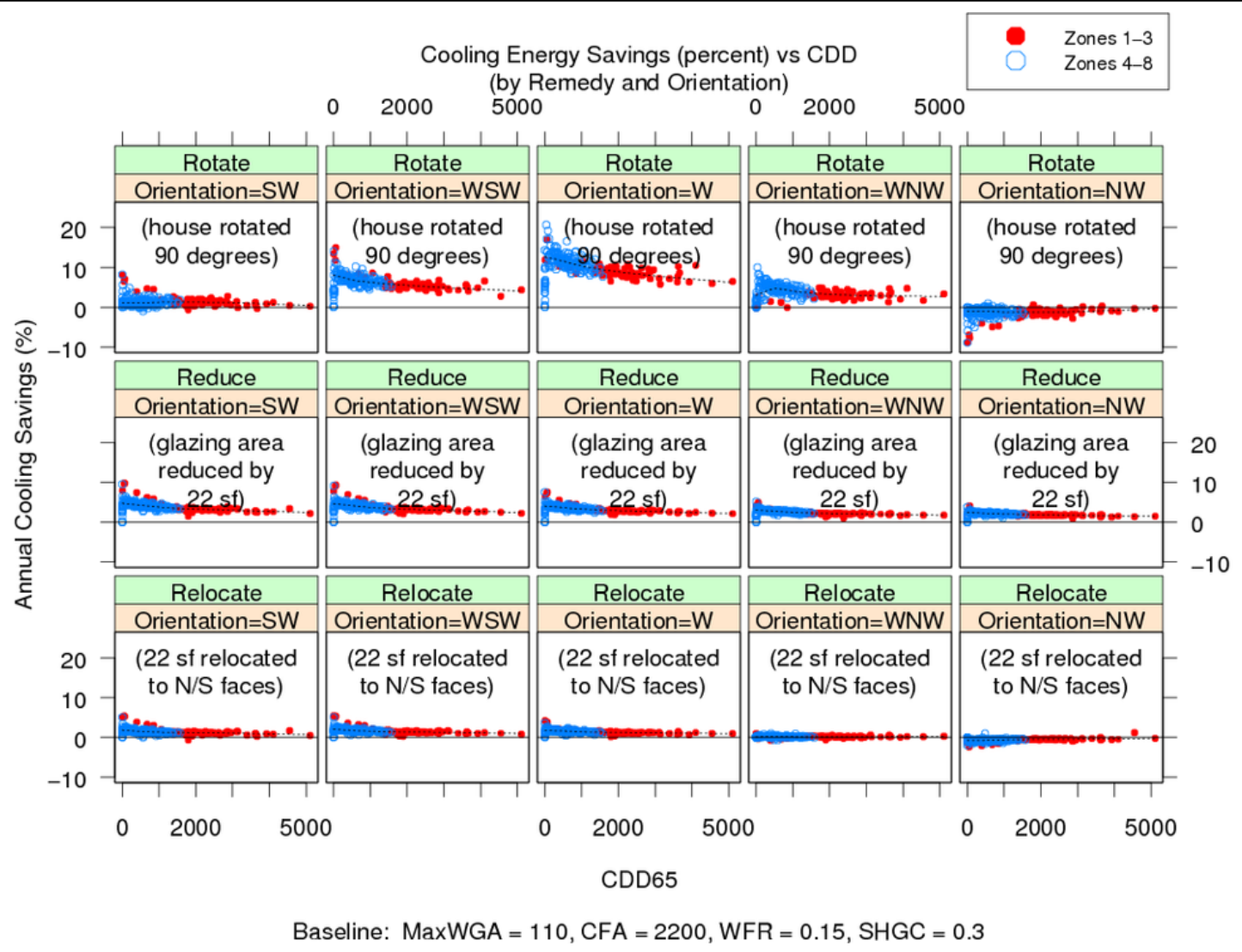

Figure 9a: Parametric Analysis of Orientation-Cooling Energy Savings (percent)

Each panel shows 239 DOE-2 simulations. The three rows correspond to the three remedies builders might employ to bring a home into compliance. The five columns represent five orientations of the home (prior to any rotation). Each orientation represents west or some departure from west, ranging from -45 degrees (SW) to +45 degrees (NW). Column $3(W)$ is the baseline. 


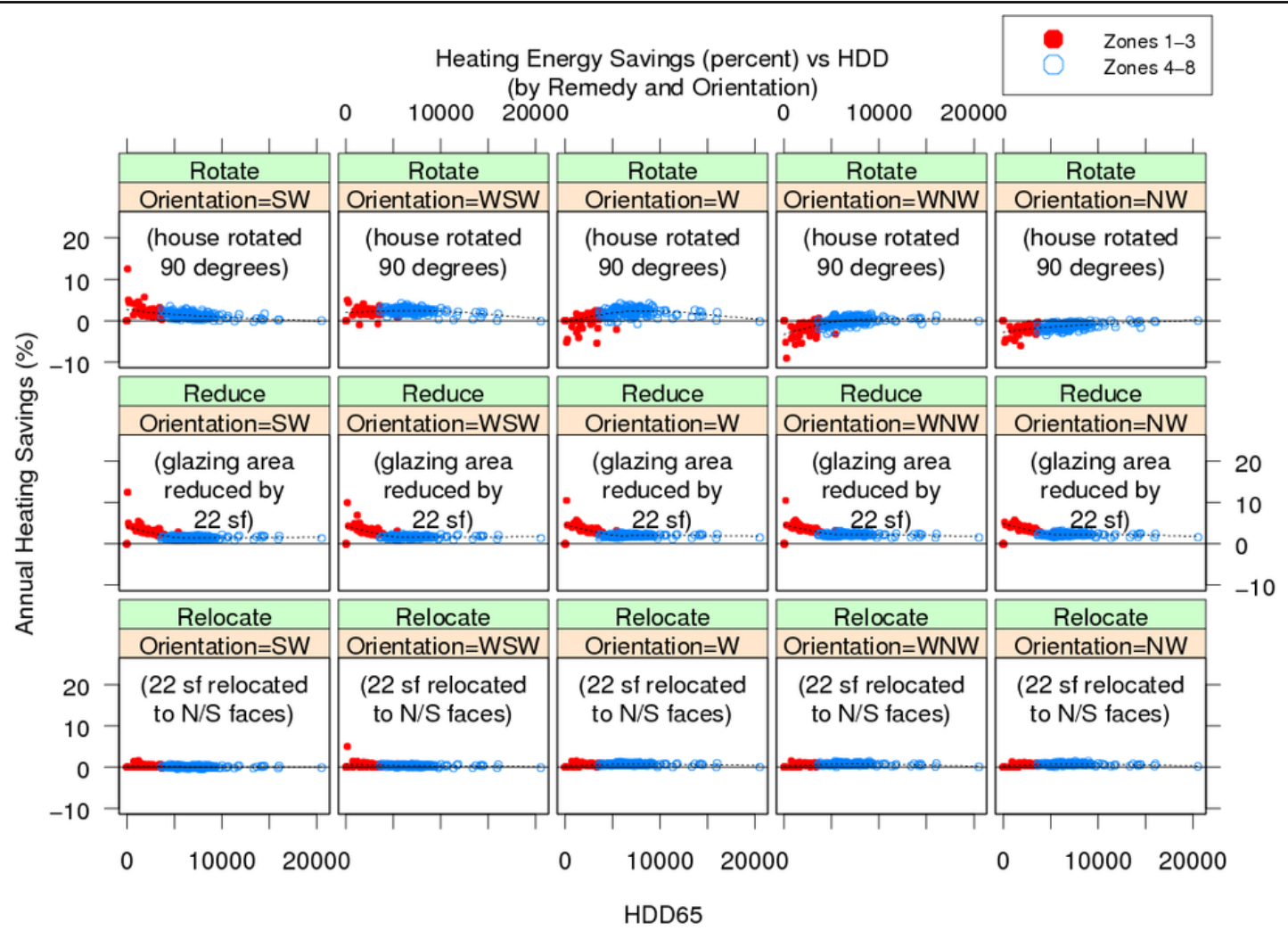

Baseline: $\operatorname{MaxWGA}=110, \mathrm{CFA}=2200, \mathrm{WFR}=0.15, \mathrm{SHGC}=0.3$

Figure 9b: Parametric Analysis of Orientation-Heating Energy Savings (percent)

Each panel shows 239 DOE-2 simulations. The three rows correspond to the three remedies builders might employ to bring a home into compliance. The five columns represent five orientations of the home (prior to any rotation). Each orientation represents west or some departure from west, ranging from -45 degrees (SW) to +45 degrees (NW). Column $3(W)$ is the baseline. 


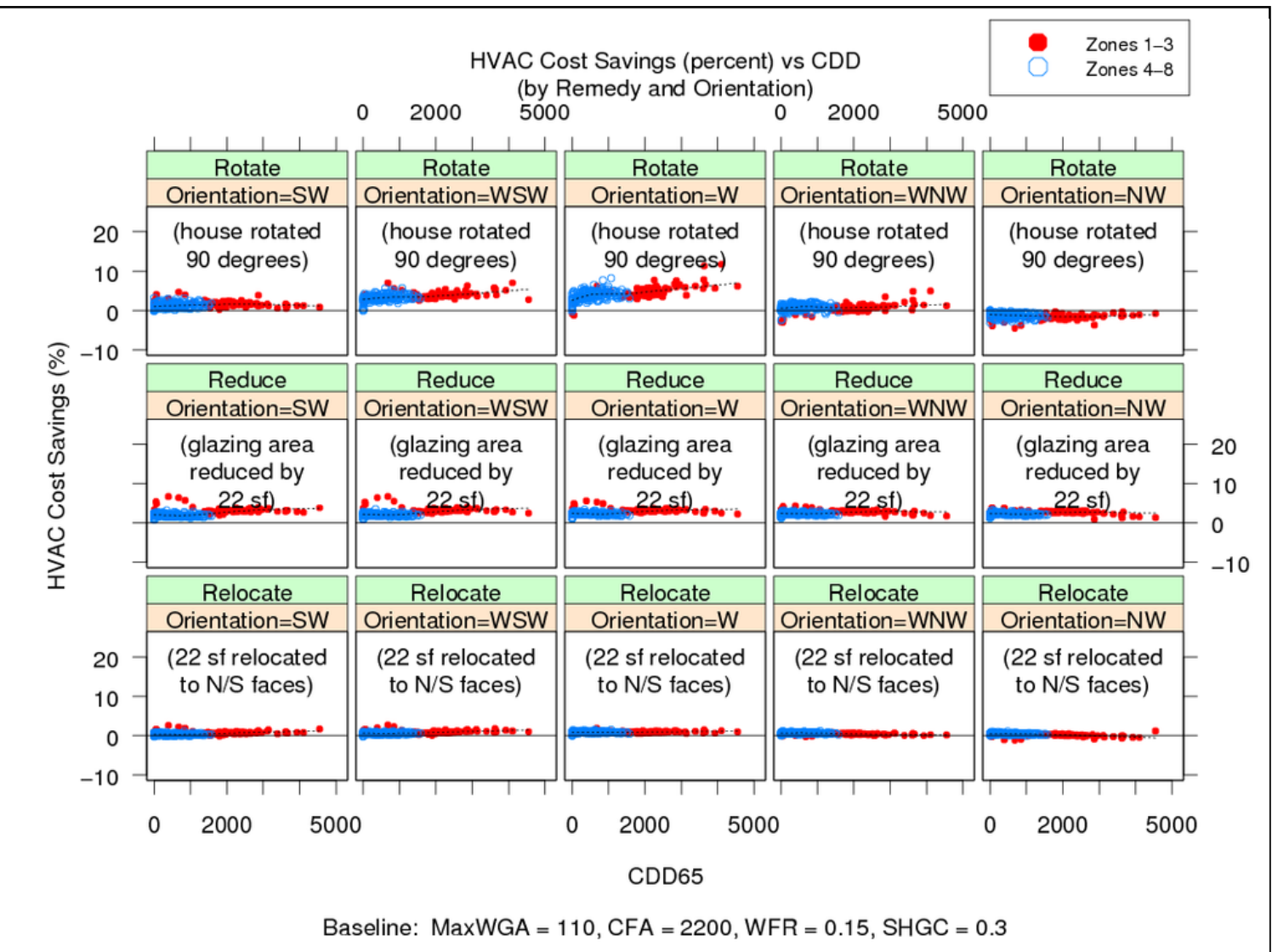

Figure 9c: Parametric Analysis of Orientation-Energy Cost Savings (percent) Each panel shows 239 DOE-2 simulations. The three rows correspond to the three remedies builders might employ to bring a home into compliance. The five columns represent five orientations of the home (prior to any rotation). Each orientation represents west or some departure from west, ranging from -45 degrees (SW) to +45 degrees (NW). Column $3(W)$ is the baseline. 


\section{Parameter: Solar Heat Gain Coefficient (SHGC, p.u.)}

Solar Heat Gain Coefficient directly affects the quantity of solar energy entering a house. The baseline SHGC was set to match the 2009 IECC's southern-zone maximum of 0.3. However, because the SHGC can be significantly different in northern zones or southern zones where compliance trade-offs are made, we have analyzed the impacts of varying SHGC. The values analyzed range from 0.2 to 0.5 . For zones $1-3$, the baseline SHGC is 0.3 , while for the northern zones, a value of 0.4 might better represent a typical baseline.

\section{Cooling Energy Savings}

Figure 10a shows the impact of SHGC on cooling energy savings. For the Relocate and Rotate remedies, relative (percent) cooling savings appear to be insensitive to SHGC. For the Reduce remedy, percent savings appear to scale with SHGC.

\section{Heating Energy Savings}

The sensitivity of heating energy savings to SHGC is shown in Figure 10b. There is very little change in the relative (percent) savings regardless of remedy or SHGC.

\section{Energy Cost Savings}

Figure 10c shows the sensitivity of overall energy cost to changes in SHGC. Relative (percent) cost savings appear to be positive regardless of remedy or SHGC, indicating that the proposed code change is robust to trade-offs that involve the SHGC and to future code changes that might modify SHGC. The absolute magnitude of energy cost savings would, of course, vary with SHGC, but the impact of applying one of the three remedies analyzed here to comply with the proposed limit on west-facing glazing would not have any perverse effects but would virtually always have a net benefit on HVAC costs. 


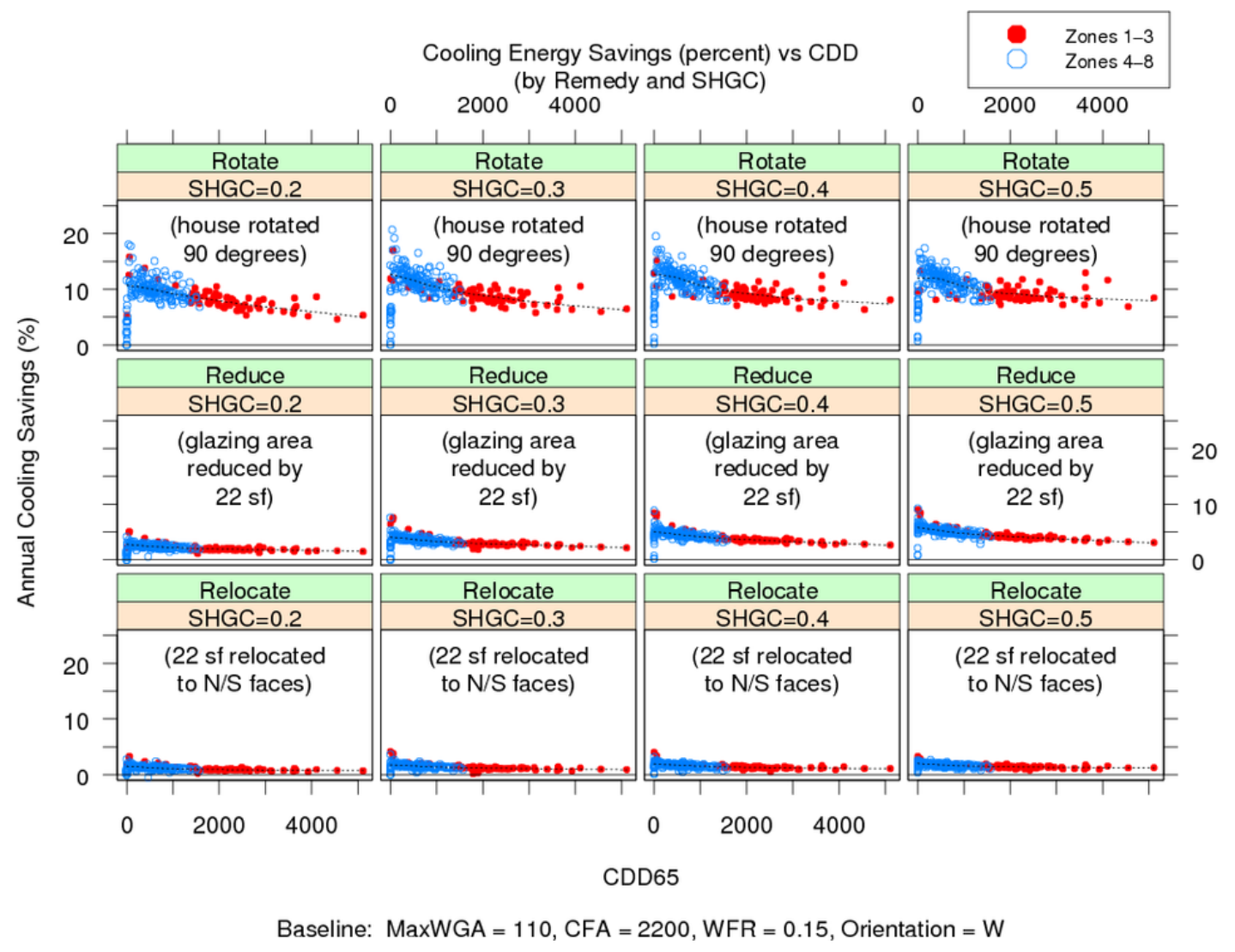

Figure 10a: Parametric Analysis of Solar Heat Gain Coefficient-Cooling Energy Savings (percent)

Each panel shows 239 DOE-2 simulations. The three rows correspond to the three remedies builders might employ to bring a home into compliance. The four columns represent four values of SHGC. Column $2(0.3)$ is the baseline for southern zones, while column 4 might be a more applicable baseline for northern zones. 


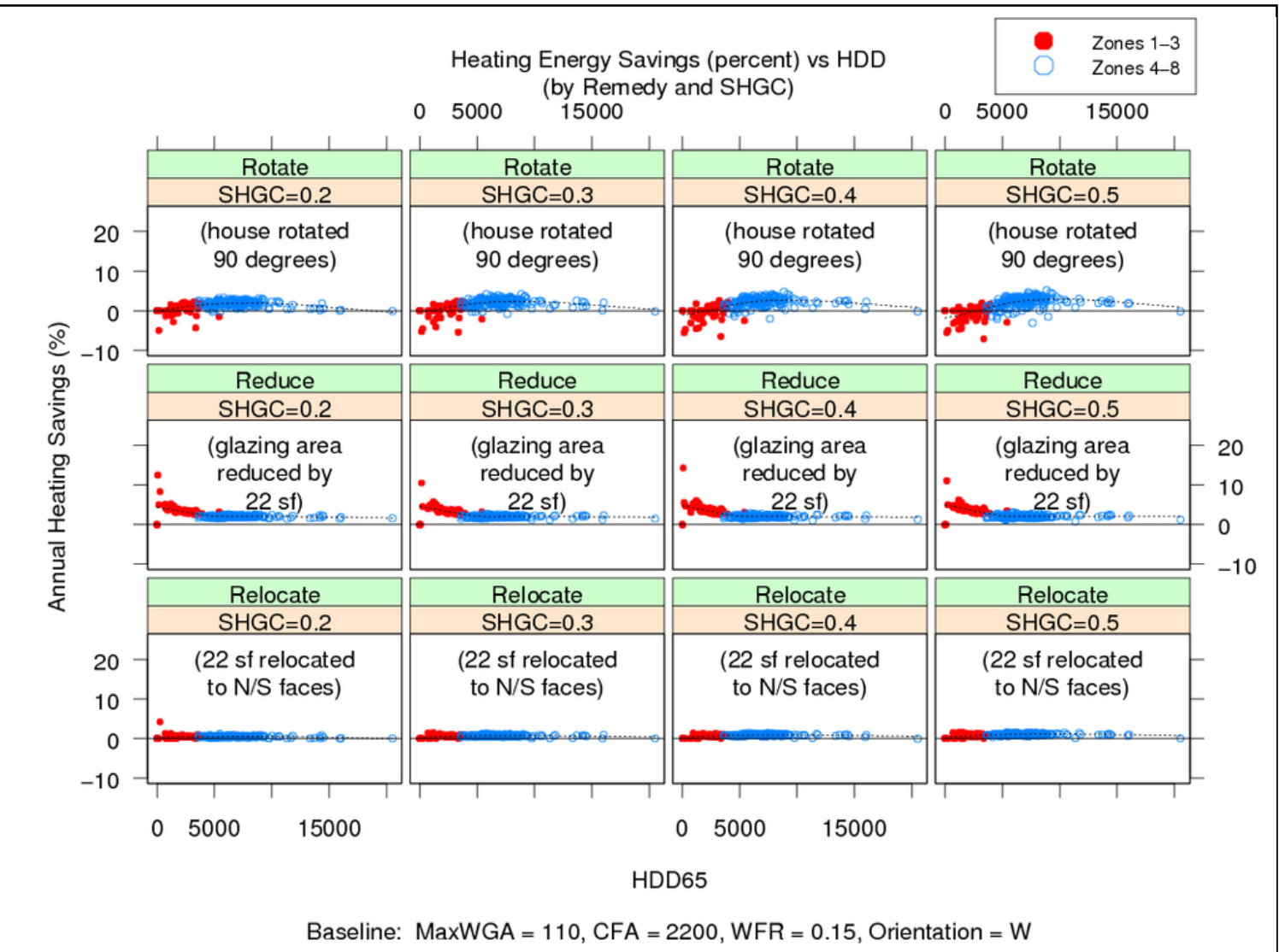

Figure 10c: Parametric Analysis of Solar Heat Gain Coefficient-Heating Energy Savings (percent)

Each panel shows 239 DOE-2 simulations. The three rows correspond to the three remedies builders might employ to bring a home into compliance. The four columns represent four values of SHGC. Column $2(0.3)$ is the baseline for southern zones, while column 4 might be a more applicable baseline for northern zones. 


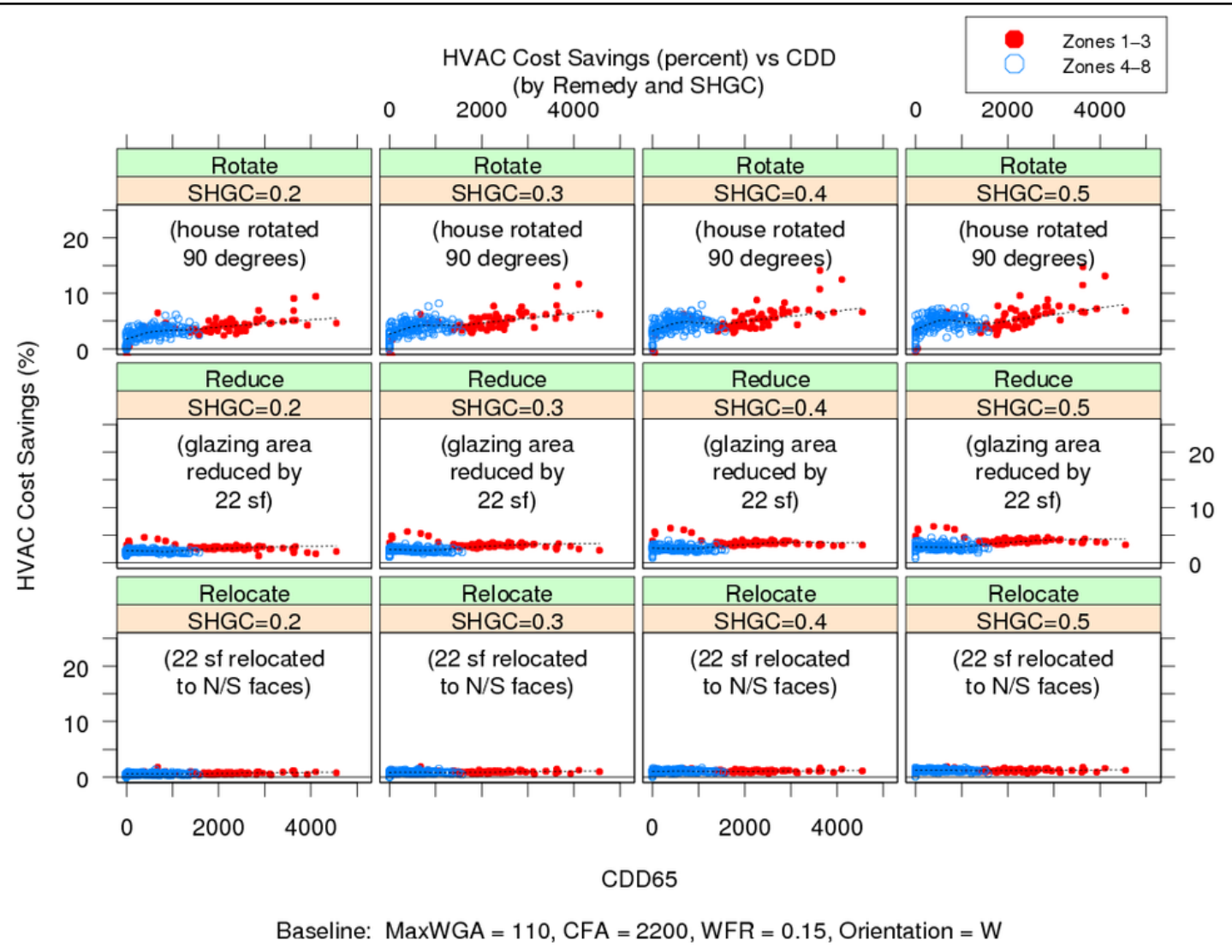

Figure 10c: Parametric Analysis of Solar Heat Gain Coefficient-Energy Cost Savings (percent)

Each panel shows 239 DOE-2 simulations. The three rows correspond to the three remedies builders might employ to bring a home into compliance. The four columns represent four values of SHGC. Column $2(0.3)$ is the baseline for southern zones, while column 4 might be a more applicable baseline for northern zones. 


\section{Peak Impact Analysis}

Although the purpose of the IECC is to promote the effective use of energy and the primary purpose of this analysis is to evaluate the proposed code change's impact on energy consumption, it is worthwhile to also examine the impact on a home's peak load. In many locations the management of afternoon cooling peaks is a high priority because of distribution infrastructures that are operating at or above design capacity, the need to manage electric generation resources, and the need to manage local pollutant emissions. The proposed code change analyzed here is ideally suited to lowering the cooling peak because it regulates a source of heat gain (solar gains through west-facing glazing) that is most intense during the times when most electric systems experience their daily peaks.

Figure 11 shows the impact of the proposed change on the baseline prototype building's maximum cooling load. For each remedy, the corresponding panel shows the relative (percent) reduction in maximum cooling load for all 239 TMY2 locations. Cooling peak reductions for the baseline building, which has an excess west-facing glazing area of only $22 \mathrm{ft}^{2}$, are roughly 4\% to 5\% for the Reduce remedy, 2\% to 3\% for the Relocate remedy, and scattered broadly around an average approaching $10 \%$ for the Rotate remedy. While cooling peaks actually increase (negative reductions in the scatterplots) in some locations, the average is clearly toward a substantial benefit. These results, of course, represent only the baseline prototype, with its average size and relatively modest 22- $\mathrm{ft}^{2}$ excess of west-facing glazing. For larger homes and home designs with higher west-facing glazing areas, the relative cooling peak reduction can be considerably higher. The next section presents some parametric analyses. 


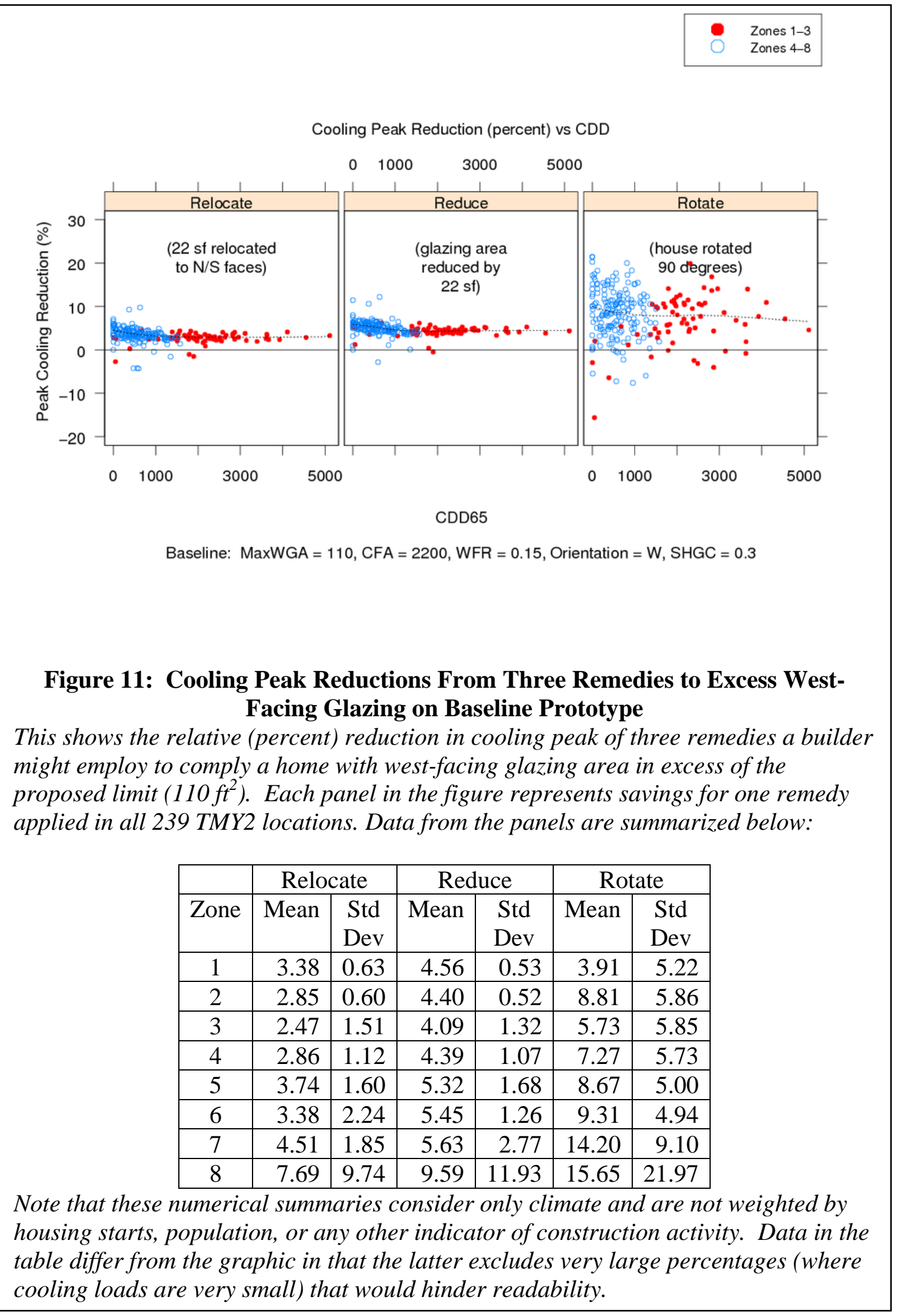




\section{Parametric Peak Analysis}

\section{Parameter: Maximum Allowable West-Facing Glazing Area (MaxWGA, $\mathrm{ft}^{2}$ )}

Unsurprisingly, Figure 12 shows that lowering the MaxWGA (making it more stringent) results in greater relative reductions in cooling peak load for the Relocate and Reduce remedies. Similarly, raising MaxWGA (loosening the restriction) results in considerably less cooling peak benefit, even zero benefit where the restriction becomes larger than the baseline home's west-facing glazing area. As was observed for the energy impacts, rotating the home has roughly constant impact on peak cooling reduction, regardless of MaxWGA (until the limit exceeds the baseline home’s west-facing glazing area).

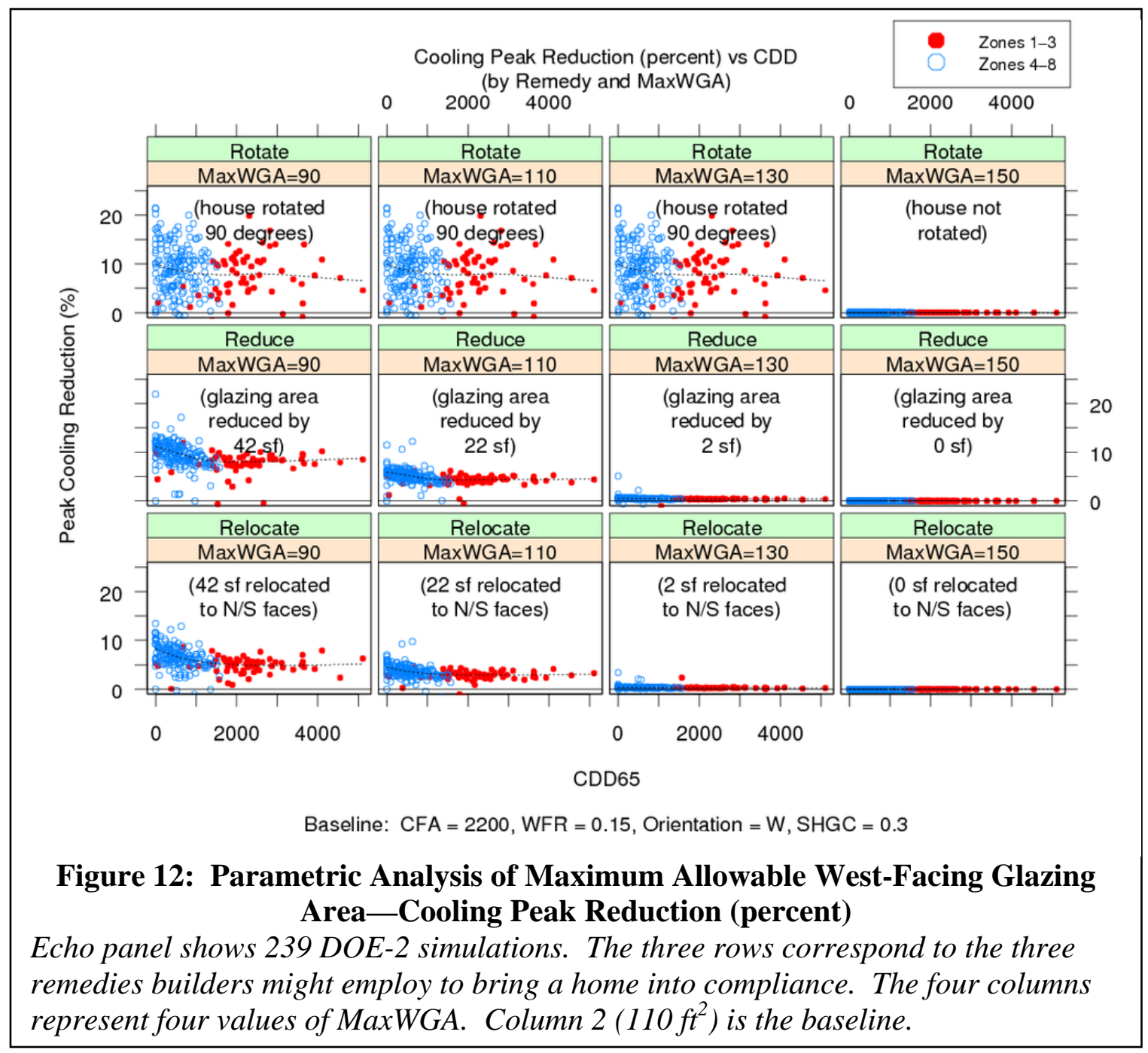




\section{Parameter: Conditioned Floor Area (CFA, $\mathrm{ft}^{2}$ )}

As was observed for energy impacts, relative reductions in peak cooling are very sensitive to the conditioned floor area. Figure 13 shows that small homes with average window-floor ratios are unaffected by the proposed restriction. Larger homes show progressively greater relative reductions in peak cooling load, with the average reduction for the Reduce remedy approaching $20 \%$ for a $5000-\mathrm{ft}^{2}$ home. Note, however, that for homes this large it may be impractical to relocate or reduce sufficient glazing to achieve compliance by those methods only. Rotating the home, as is generally the case, results in compliance and reduces peak cooling by a roughly constant percentage.

In summary, smaller homes see low or in some cases no cooling peak benefit while larger homes see a benefit approaching 10\% for CFA beyond $3000 \mathrm{ft}^{2}$ or so. Other remedies that might employ the Performance compliance path would likely fall into the same range, as the proposed home would be compared against an advantageously oriented home.

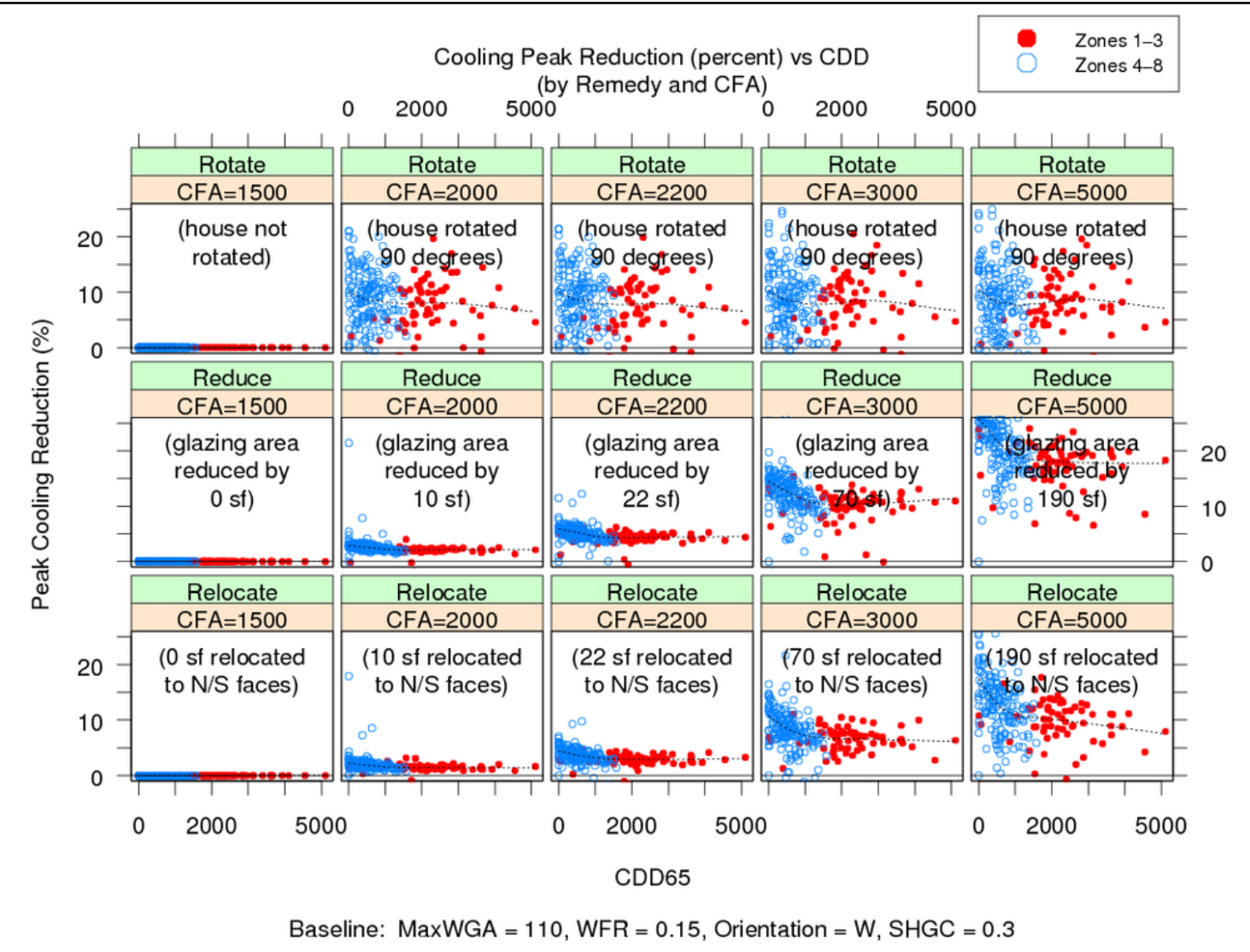

Figure 13: Parametric Analysis of Conditioned Floor Area-Cooling Peak Reduction (percent)

Each panel shows 239 DOE-2 simulations. The three rows correspond to the three remedies builders might employ to bring a home into compliance. The five columns represent five values of CFA. Column $3\left(2200 \mathrm{ft}^{2}\right)$ is the baseline. 


\section{Parameter: Window-Floor Ratio (WFR, p.u.)}

As shown in Figure 14, varying window-floor ratio exhibits patterns similar to those of varying conditioned floor area. This is not unexpected since both parameters change the overall glazing area of the home. The Relocate and Reduce remedies show progressively greater cooling peak benefit as WFR increases, while the Rotate remedy has roughly constant relative (percent) cooling peak reduction. As with CFA, homes with very large WFR may be difficult to comply using only relocations and reductions of west-facing windows. The Rotate remedy probably establishes the reasonable upper bound of peak benefit, which again approaches $10 \%$.

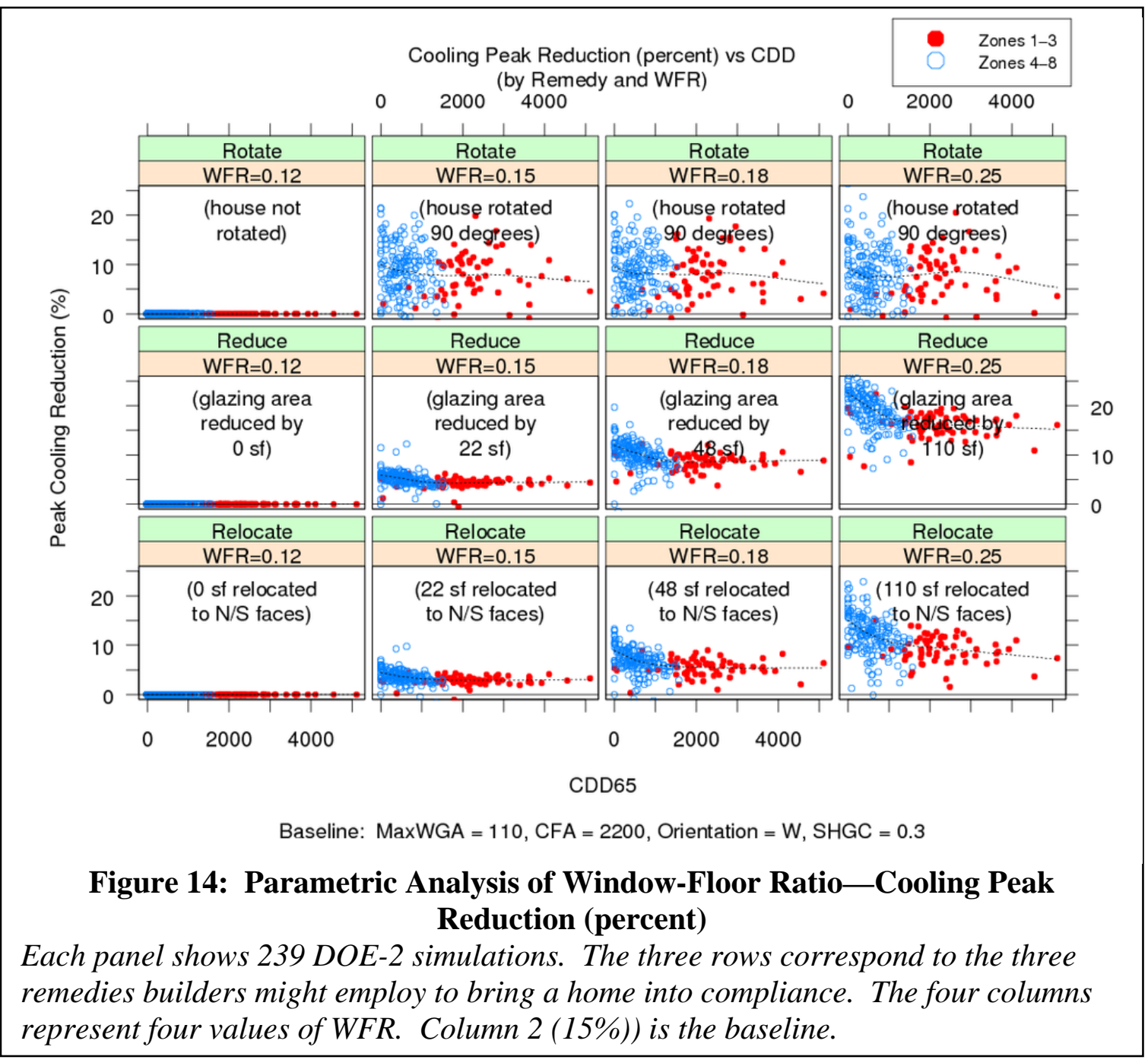




\section{Parameter: Orientation of Home (Orientation, compass designation)}

Orientation of the home is an important parameter. The energy code should not encourage reorienting homes if doing so might have detrimental impacts. Figure 15 shows the relative (percent) reduction in peak cooling resulting from applying the three remedies to buildings facing between southwest and northwest. As might be expected, the Reduce remedy results in a benefit to peak cooling regardless of initial orientationlowering the total glazing area is always good for the peak load. The Relocate strategy has benefits in most starting orientations, but the benefit diminishes to near zero at a northwest orientation. The Rotate strategy is most sensitive to the initial orientation, with benefits going negative at a northwest orientation and clustered around zero at westnorthwest.

In summary, these results imply the same conclusion implied by the energy savings sensitivity analysis - that the proposed restriction on west-facing glazing should not be applied to homes whose "west" face points more than 30 degrees north of true west.

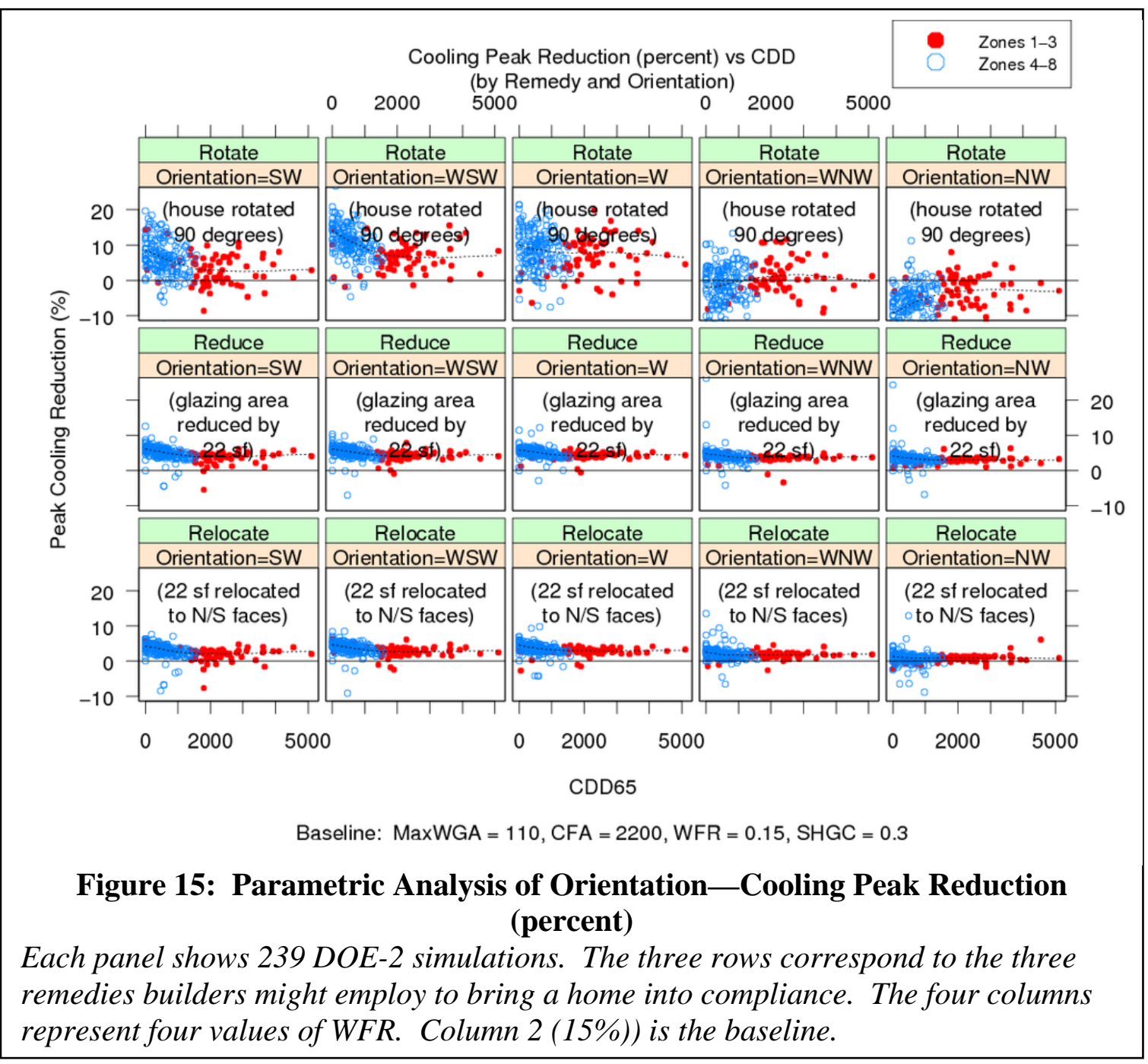




\section{Parameter: Solar Heat Gain Coefficient (SHGC, p.u.)}

Figure 16 shows the sensitivity of cooling peak load reduction (percent) to changes in the solar heat gain coefficient of the home's glazing. The sensitivities are modest to nonexistent for all three remedies. Although relative reductions in peak are higher for higher SHGCs, the differences are slight. When analyzed in terms of relative (percent) peak reductions, the benefits of the proposed code change are almost constant at a few percent for the Relocate remedy, roughly five percent for the Reduce remedy, and about eight to 10 percent for the Rotate remedy.

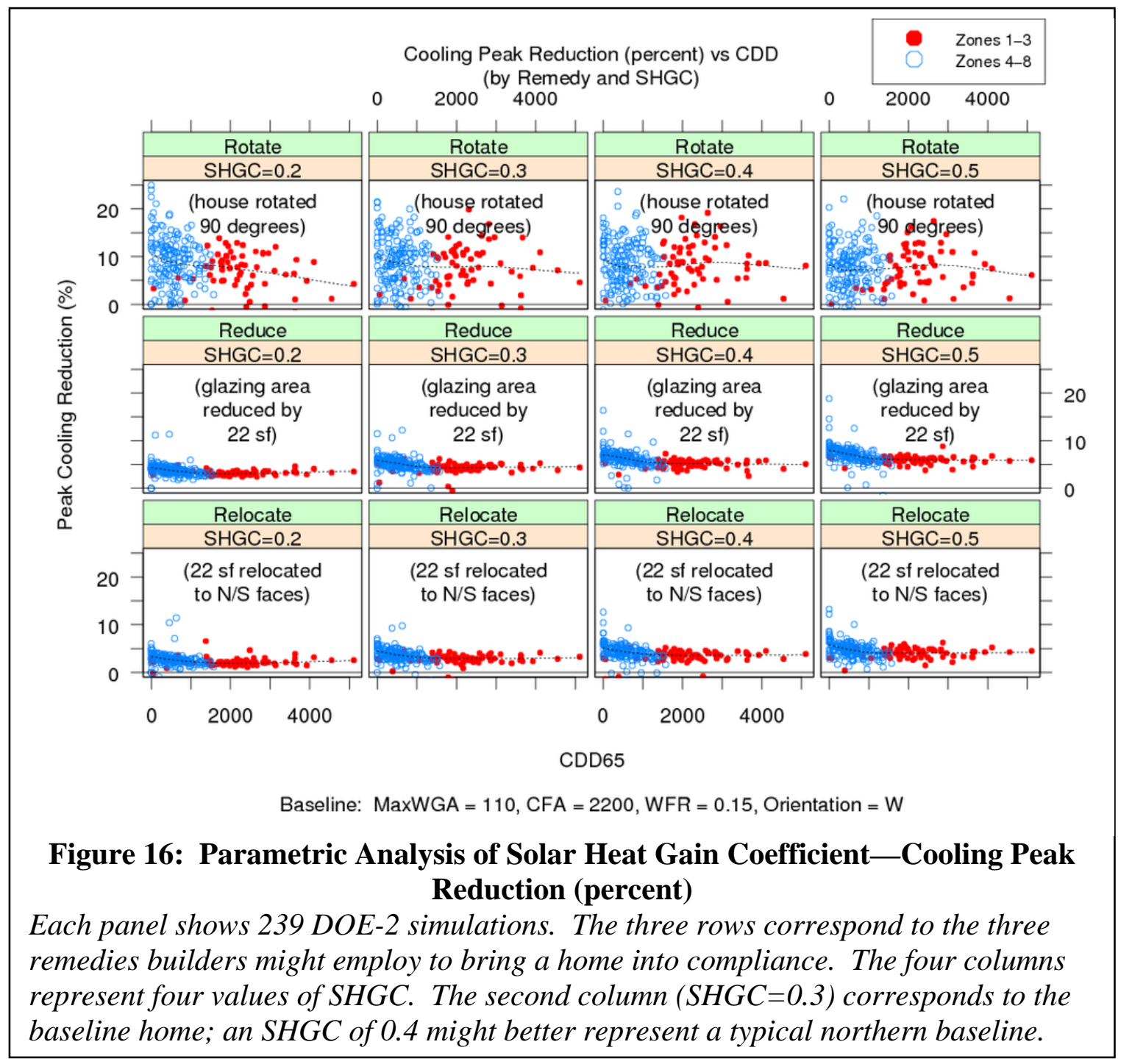

